Review

\title{
New Materials and Effects in Molecular Nanomagnets
}

\author{
Tomasz Blachowicz ${ }^{1}$ (D) and Andrea Ehrmann ${ }^{2, *}$ (D) \\ 1 Center for Science and Education-Institute of Physics, Silesian University of Technology, \\ 44-100 Gliwice, Poland; tomasz.blachowicz@polsl.pl \\ 2 Faculty of Engineering and Mathematics, Bielefeld University of Applied Sciences, 33619 Bielefeld, Germany \\ * Correspondence: andrea.ehrmann@fh-bielefeld.de
}

check for

updates

Citation: Blachowicz, T.; Ehrmann A. New Materials and Effects in Molecular Nanomagnets. Appl. Sci. 2021, 11, 7510. https://doi.org/ 10.3390/app11167510

Academic Editor: Costica Caizer

Received: 4 July 2021

Accepted: 14 August 2021

Published: 16 August 2021

Publisher's Note: MDPI stays neutral with regard to jurisdictional claims in published maps and institutional affiliations.

Copyright: (c) 2021 by the authors. Licensee MDPI, Basel, Switzerland. This article is an open access article distributed under the terms and conditions of the Creative Commons Attribution (CC BY) license (https:// creativecommons.org/licenses/by/ $4.0 /)$.

\begin{abstract}
Molecular magnets are a relatively new class of purely organic or metallo-organic materials, showing magnetism even without an external magnetic field. This interdisciplinary field between chemistry and physics has been gaining increased interest since the 1990s. While bulk molecular magnets are usually hard to build because of their molecular structures, low-dimensional molecular magnets are often easier to construct, down to dot-like (zero-dimensional) structures, which are investigated by different scanning probe technologies. On these scales, new effects such as superparamagnetic behavior or coherent switching during magnetization reversal can be recognized. Here, we give an overview of the recent advances in molecular nanomagnets, starting with single-molecule magnets (0D), typically based on $\mathrm{Mn}_{12}, \mathrm{Fe}_{8}$, or $\mathrm{Mn}_{4}$, going further to single-chain magnets (1D) and finally higher-dimensional molecular nanomagnets. This review does not aim to give a comprehensive overview of all research fields dealing with molecular nanomagnets, but instead aims at pointing out diverse possible materials and effects in order to stimulate new research in this broad field of nanomagnetism.
\end{abstract}

Keywords: single-molecule magnet (SMM); single-chain magnet (SCM); molecular nanomagnet; molecular structure; information storage

\section{Introduction}

When thinking about nanomagnets from a physicist's point of view, usually zerodimensional (0D) or one-dimensional (1D) magnets will come to mind. Such nanomagnets may be formed, e.g., from the ferromagnets iron, nickel, cobalt, or permalloy, or from the ferrimagnets of magnetite or nickel ferrite, to name just a few [1-5]. Ferromagnetic materials contain elementary magnets for which a parallel orientation is energetically favored, while ferrimagnets can be imagined as containing two antiparallely oriented ferromagnetic sublattices with different magnitudes of magnetization, in this way also resulting in a net magnetization. Diverse shapes can be thought of, from square or round nanodots $[6,7]$ to magnetic nanowires, e.g., those used in the so-called Racetrack memory [8-10], to more complicated shapes, including 3D particles [11-13]. Combining different magnetic materials, e.g., a ferromagnetic and an antiferromagnetic one, can result in additional effects as a result of the surface interactions, such as the exchange bias [14-17].

Molecular magnets, in principle, have a similar hierarchy. Starting from singlemolecule magnets (SMM) [18-20] and single-chain magnets (SCM) [21-23], more complex structures are also possible [24-26]. In general, molecular nanomagnets can be built without the aforementioned magnetic elements [27]; however, highly interesting molecular nanomagnets can be created by adding $\mathrm{Mn}_{12}, \mathrm{Fe}_{8}, \mathrm{Mn}_{4}$, or other metallic elements [28-30].

Here, we give a brief overview of the principle of why even purely organic molecules can exhibit ferromagnetism, followed by sections reporting on recent advances in SMMs, SCMs, and other structures prepared from purely organic molecules or containing typical inorganic ions, such as $\mathrm{Mn}_{12}$ and $\mathrm{Fe}_{8}$, concluding with possible applications, e.g., in data storage. The review is organized as follows: Starting with a brief overview of the magnetic 
anisotropy of metal centers in molecular complexes and magnetic interactions via ligands, we review the most recent findings dealing with SMMs, followed by SCMs. In both sections, the information is ordered according to materials or material classes, respectively. These mainly experimental sections are followed by an overview of the recent theoretical approaches and methods. Finally, the most recent reviews dealing with special fields of molecular magnets are provided for deeper reading.

\section{Single-Ion Anisotropies}

Single-molecule magnets can be prepared, amongst others, from lanthanides and actinides, such as the lanthanide ion $\mathrm{Dy}^{3+}$, with some lanthanide elements being known to be part of the strongest recently known magnets [31]. SMMs based on such f-elements can show very high anisotropy barriers, blocking magnetization reversal, and have hysteretic behavior at significantly higher temperatures than other SMMS.

In these SMMs, a strong magnetic anisotropy of the metal center plays the most important role for their magnetic properties. Necessary prerequisites for this are a doublydegenerate ground state - to reach bistability of the ground state-and a high quantum number $\pm m_{j}$-leading to a high magnetic moment when the ground state is mostly populated [31]. This is generally the case for Dy(III) ions and, in a strictly axial crystal field symmetry, also for $\mathrm{Tb}(\mathrm{III})$ ions. Furthermore, a large separation between this bistable ground state $\pm m_{j}$ and the first excited state is necessary, as the energy required for relaxation is often correlated with this separation.

Calculating the $4 \mathrm{f}$ electronic structures for lanthanide ions and the corresponding optimum crystal fields, Rinehart and Long theoretically explained the most often used axially-coordinated ligand environment that is optimum for Dy(III), and also suggested using $\mathrm{Tm}$ (III) and $\mathrm{Yb}$ (III) ions as part of SMMs [31].

Design strategies based on crystal-field theory were suggested by Liu et al., who suggested high-performance Ln-based SMMs with very slow magnetization relaxation, and discussed some representative Ln-SMMs with special local symmetries [32]. However, the authors also mentioned the challenges to realize the practical magnetic characterization of these high-performance SMMs.

The role of the single-ion anisotropy is discussed in the literature by many other authors, e.g., as part of a synergic effect with magnetic exchange interactions [33-35].

It should be mentioned that the aforementioned relaxation processes are less well understood in lanthanide-based SMMs than in SMMs containing transition-metal complexes. For Ln-SMMs, multiple relaxation pathways are mentioned, such as the reversal of thermally activated spins at high temperatures and tunnel relaxation at low temperatures, as well as spin-lattice relaxation or field-induced multiple relaxations, with a general tendency to show multiple relaxation processes, as is visible in two-step or even more complicated relaxation processes [36].

\section{Magnetic Interactions via a Ligand}

Generally, magnetic interactions via ligands can be assumed to be similar to those found in inorganic materials. As organic molecules are usually isolating, the magnetic interactions are more localized. In the easiest approach, singly occupied molecular orbitals (i.e., unpaired electrons) inside a molecule are regarded as magnetic orbitals, with their relative orientation being responsible for ferromagnetic or antiferromagnetic coupling $[37,38]$. This exchange interaction works directly between unpaired electrons or via a ligand, in this case usually described as a super-exchange interaction. This interaction is depicted in more detail in Figure 1 [39]. 
a) Ferromagnetic $\left(\theta_{\mathrm{Ni}-\mathrm{O}-\mathrm{Ni}}=90^{\circ}\right)$

b) Antiferromagnetic $\left(\theta_{\mathrm{Ni}-\mathrm{O}-\mathrm{Ni}}=180^{\circ}\right)$
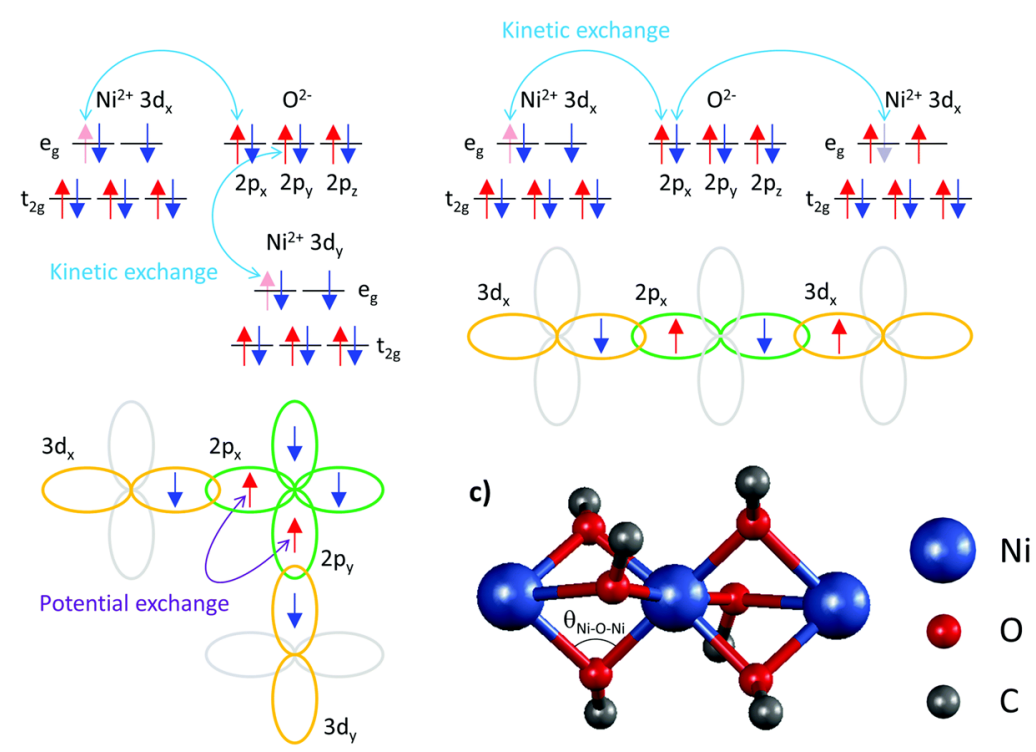

Figure 1. Super-exchange coupling between nearest-neighbor $3 \mathrm{~d}$ orbitals of $\mathrm{Ni}$ via the ligands of $\mathrm{O}^{2-}$ (2p orbitals). (a) In the case of a $90^{\circ}$ angle between $\mathrm{Ni}-\mathrm{O}-\mathrm{Ni}$, super-exchange results in a ferromagnetic coupling between the orthogonal oxygen $2 \mathrm{p}$ orbitals; (b) for an angle of $180^{\circ}$ between $\mathrm{Ni}-\mathrm{O}-\mathrm{Ni}$, an antiferromagnetic coupling occurs due to the nickel and oxygen orbitals overlapping; and (c) geometry of nickel(II) acetylacetonate (Ni(acac) $)_{2}$ ) molecular magnets. From ref. [39], originally published under a CC-BY license.

In addition, a double exchange can occur in mixed valence systems (e.g., metal ions in different oxidation states, such as $\mathrm{Mn}^{\mathrm{III}}$ and $\mathrm{Mn}^{\mathrm{IV}}$ ), describing the fast hopping of unpaired electron between the ions, i.e., delocalization of the valences. This results in a ferromagnetic coupling, as the transferred spin must be parallel to the other $\mathrm{Mn}^{4+}$ spins because of the Pauli principle [40,41].

\section{Single-Molecule Magnets}

Probably the most interesting applications of single-molecule magnets are for information storage and spintronic devices. While common magnetic nanoparticles reach the superparamagnetic limit for dimensions below 10-100 nm, single-molecule magnets with transition-metal ions can be used for data storage, while being much smaller [42]. For the first SMM reported, antiferromagnetic interactions between the spins of $\mathrm{Mn}^{\mathrm{IV}}$ and $\mathrm{Mn}{ }^{\mathrm{III}}$ ions in the molecule $\left[\mathrm{Mn}_{12} \mathrm{O}_{12}\left(\mathrm{CH}_{3} \mathrm{COO}\right)_{16}\left(\mathrm{H}_{2} \mathrm{O}\right)_{4}\right]$ were found to result in a large spin ground state with the spin quantum number $S=10$, and in very long magnetization relaxation times, making such a bistable molecule highly interesting for data storage [43,44]. It should be mentioned that the coercive fields in this system, measured by hysteresis loops, depend not only on the temperature, but also on the field sweep rate [18]. Gatteschi et al. attributed the magnetic uniaxial anisotropy of this system to the magnetic anisotropy of the eight $\mathrm{Mn}^{+3}$ in the molecule, which show zero-field splitting due to the Jahn-Teller elongation of some bonds and the spin-orbit interactions [45]. In this system, hysteresis loops are also modified in comparison with "normal" loops, showing steps at some external magnetic fields due to the resonant tunneling between levels with identical energies in the two energetically favored orientations [46,47].

Another often investigated complex is $\mathrm{Fe}_{8}$ in the form of the cluster $\left[\mathrm{Fe}_{8} \mathrm{O}_{2}(\mathrm{OH})_{12}(\operatorname{tacn})_{6}\right]^{8+}$, with (tacn) indicating a macrocyclic ligand. However, here, the relaxation is temperatureindependent below a temperature of $0.36 \mathrm{~K}$ or $0.4 \mathrm{~K}$, respectively, as opposed to $\mathrm{Mn}_{12}$, because tunneling is only possible between the lowest energy levels, i.e., the levels with magnetic quantum numbers $m_{s}= \pm 10[48,49]$. Similarly, $\left[\mathrm{Mn}_{4} \mathrm{O}_{3} \mathrm{Cl}_{2}\left(\mathrm{O}_{2} \mathrm{CCH}_{3}\right)_{3}(\mathrm{dbm})_{3}\right]$ with the mono-anion of dibenzoylmethane $\mathrm{dbm}^{-}$(usually named $\mathrm{Mn}_{4}$ ) with an $S=9 / 2$ ground 
state shows a temperature-independent relaxation below a temperature of $0.6 \mathrm{~K}$ for the same reason [50].

It should be mentioned that, as mentioned in Sections 2 and 3, the magnetic behavior of these clusters based on $\mathrm{Mn}_{12}, \mathrm{Mn}_{4}$, or $\mathrm{Fe}_{8}$ is defined by the magnetic exchange, which is necessary for the high ground state spin. However, for lanthanide-based SMMs, magnetic exchange can even be disadvantageous and is not necessary to create an SMM. This should be taken into account for the lanthanide-based SMMs discussed next.

One disadvantage of the aforementioned single-molecule magnets is their very small blocking temperature, typically below the temperature of liquid helium. Ideally, magnetic properties should be reached above the temperature of liquid nitrogen, i.e., $77 \mathrm{~K}$. This is one of the challenges diverse research groups have been working on during the last decades [51].

Recently, Li et al. reported on a relatively large blocking temperature of $9 \mathrm{~K}$ found in highly-axial lanthanide SMMs of the form [Dy(Cy $\left.\mathrm{CO})_{2} \mathrm{I}_{3}\left(\mathrm{CH}_{3} \mathrm{CN}\right)\right]$. The iodide ions have a large volume and low surface charge density, and serve as weak donors in this six-coordinate neutral molecule. The reduced ligand field strength results in a strongly axial crystal field in this SMM, leading to strong crystal-field splitting and high axial orientation [52].

A recipe for higher blocking temperatures was recently proposed by Chiesa et al. They used $\left[\mathrm{Dy}\left(\mathrm{C}_{5} \mathrm{H}_{2}^{\mathrm{t}} \mathrm{Bu}_{3}-1,2,4\right)_{2}\right]\left[\mathrm{B}\left(\mathrm{C}_{6} \mathrm{~F}_{5}\right)_{4}\right]$ as a model complex to investigate the relaxation mechanisms that they found based on Orbach, Raman, and quantum tunneling of the magnetization processes, i.e., some of the special relaxation pathways mentioned in Section 2. Based on these results, they could predict these processes' temperature and field dependencies, showing that suppressing the Raman mechanism is important to increase the blocking temperature. In general, they concluded that a crystal with weakly-interacting rigid molecules was necessary to reach the requirements of the soft acoustic branches and high-energy optical modes [53], which was revealed from the phonon density of states (DOS) computed ab initio.

An experimental approach was chosen by Jin et al. They prepared two different disprosiacarboranes, $\left[\left(\mathrm{C}_{2} \mathrm{~B}_{9} \mathrm{H}_{11}\right)_{2} \mathrm{Dy}(\mathrm{THF})_{2}\right]\left[\mathrm{Na}(\mathrm{THF})_{5}\right]$ (denoted as $\left.1 \mathrm{Dy}\right)$ and $\left[(\mathrm{THF})_{3}(\mu-\right.$ $\left.\mathrm{H})_{3} \mathrm{Li}\right]_{2}\left[\left\{\eta^{5}-\mathrm{C}_{6} \mathrm{H}_{4}\left(\mathrm{CH}_{2}\right)_{2} \mathrm{C}_{2} \mathrm{~B}_{9} \mathrm{H}_{9}\right\} \mathrm{Dy}\left\{\eta^{2}: \eta^{5}-\mathrm{C}_{6} \mathrm{H}_{4}\left(\mathrm{CH}_{2}\right)_{2} \mathrm{C}_{2} \mathrm{~B}_{9} \mathrm{H}_{9}\right\}_{2} \mathrm{Li}\right]$ (named 3Dy), finding opened hysteresis loops up to $6.8 \mathrm{~K}$ in the complex 3Dy (Figure 2), i.e., a blocking temperature of $6.8 \mathrm{~K}$ and thus above the temperature of liquid helium [54].

(a)

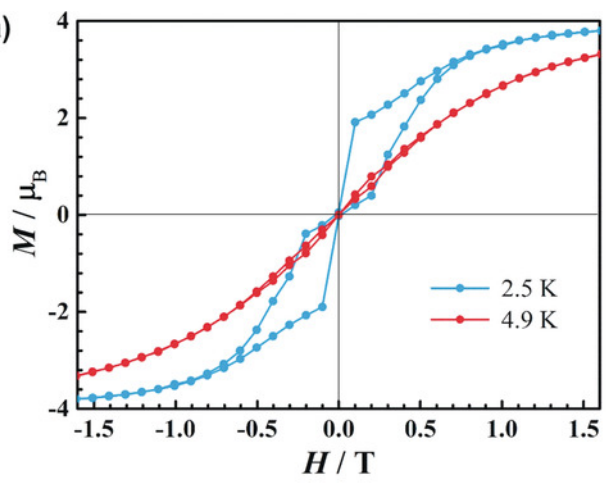

(b)

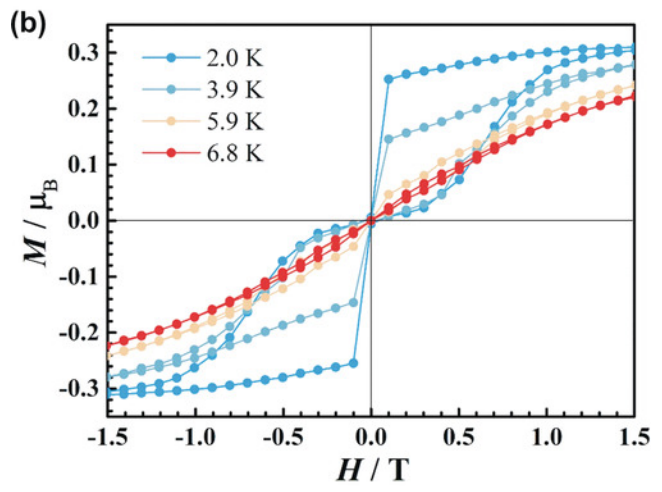

Figure 2. Hysteresis loops, measured at different temperatures in the systems (a) 1Dy; (b) 3Dy. Reprinted from [54], copyright 2020, with permission from Wiley.

Another approach was chosen by Spree et al. They investigated the fullerene-based SMMs DySc ${ }_{2} \mathrm{~N} @ \mathrm{C}_{80}$ and $\mathrm{Dy}_{2} \mathrm{ScN} @ \mathrm{C}_{80}$, as well as $\mathrm{DyLu}_{2} \mathrm{~N} @ \mathrm{C}_{80}$ and $\mathrm{Dy}_{2} \mathrm{LuN} @ \mathrm{C}_{80}$, and found blocking temperatures of $9.5 \mathrm{~K}\left(\mathrm{DyLu}_{2} \mathrm{~N} @ \mathrm{C}_{80}\right)$ and $6.9 \mathrm{~K}\left(\mathrm{DySc}_{2} \mathrm{~N} @ \mathrm{C}_{80}\right)$, combined with longer relaxation times, while the other complexes showed blocking temperatures of around $8 \mathrm{~K}$ [55]. Nie et al. found similar blocking temperatures of $9 \mathrm{~K}$ in the fullerene-based 
SMM DyErScN@ $I_{h}-\mathrm{C}_{80}$ [56]. A much higher blocking temperature of $24 \mathrm{~K}$ was observed by Velkos et al. in the azafullerene $\mathrm{Tb}_{2} @ \mathrm{C}_{79} \mathrm{~N}$ [57].

Similar blocking temperatures were found by Díaz-Ortega et al. who prepared Dy $\mathrm{III}$ single-ion magnets from $\left[\mathrm{Dy}\left(\mathrm{OPCy}_{3}\right)_{2}\left(\mathrm{H}_{2} \mathrm{O}\right)_{5}\right]\left(\mathrm{CF}_{3} \mathrm{SO}_{3}\right)_{3} \cdot 2 \mathrm{OPCy}_{3}$ (with $\mathrm{OPCy}_{3}=$ tricyclohexylphosphine oxide) [58].

Much higher values were observed by Gould et al. who compared the divalent linear metallocenes $\operatorname{Ln}\left(\mathrm{Cp}^{\mathrm{iPr} 5}\right)_{2}$ (with $\mathrm{Ln}=\mathrm{Tb}$, Dy) with the trivalent ones $\left[\mathrm{Ln}\left(\mathrm{C} \mathrm{p}^{\mathrm{iPr} 5}\right)_{2}\right]\left[\mathrm{B}\left(\mathrm{C}_{6} \mathrm{~F}_{5}\right)_{4}\right]$, and found longer relaxation times in $\mathrm{Tb}^{\mathrm{II}}$ than in $\mathrm{TB}^{\mathrm{III}}$ and longer relaxation times in $\mathrm{Dy}^{\mathrm{III}}$ than in $\mathrm{Dy}^{\mathrm{II}}$, and a similar behavior for $\mathrm{Tb}^{\mathrm{II}}$ and $\mathrm{Dy}{ }^{\mathrm{III}}$, as could be expected from the identical number of unpaired electrons in the latter. Most importantly, in $\operatorname{Tb}\left(\mathrm{Cp}^{\mathrm{iPr} 5}\right)_{2}$ they found a high blocking temperature of $52 \mathrm{~K}$ [59].

Other high blocking temperatures were found, e.g., in $\left[\left(\mathrm{Cp}^{\mathrm{iPr} 5}\right) \mathrm{Dy}\left(\mathrm{C} \mathrm{p}^{*}\right)\right]^{+}$with $\mathrm{C} \mathrm{p}^{\mathrm{iPr} 5}$ = penta-iso-propylcyclopentadienyl and $\mathrm{Cp}^{*}=$ pentamethylcyclopentadienyl, an SMM for which Guo et al. reported a blocking temperature of $80 \mathrm{~K}$, i.e., even above the temperature of liquid nitrogen [60], for the Dy ${ }^{\mathrm{III}}$ metallocenium salt $\left[\mathrm{Dy}\left(\mathrm{Cp}^{\mathrm{iPr} 4 \mathrm{R}}\right)_{2}\right]\left[\mathrm{B}\left(\mathrm{C}_{6} \mathrm{~F}_{5}\right)_{4}\right]$ for $\mathrm{R}=\mathrm{Me}$, i.e., the methyl-substituted complex, with a blocking temperature of $62 \mathrm{~K}$ [61], or for the metallocenium cation $\left[\left(\mathrm{Cp}^{\mathrm{ttt}}\right)_{2} \mathrm{Dy}\right]^{+}$with $\mathrm{Cp}^{\mathrm{ttt}}=1,2,4$-tri $($ tert-butyl)cyclopentadienide, where Guo et al. measured a blocking temperature of $60 \mathrm{~K}$ [62].

While pure metal SMMs have been investigated in detail [32,63], metal complexes such as the aforementioned ones are often highly interesting. In particular, $3 \mathrm{~d}-4 \mathrm{f}$ metal complexes can add special properties to SMMs, such as a high-spin ground state and a large magnetic anisotropy [64]. The first SMM containing such a $3 \mathrm{~d}-4 \mathrm{f}$ metal complex was $\left[\mathrm{Cu}^{\mathrm{II}-} \mathrm{LTb}^{\mathrm{III}}(\mathrm{hfac})_{2}\right]_{2}$ [65]; other $3 \mathrm{~d}-4 \mathrm{f}$ complexes are, e.g., $\mathrm{Mn}_{3} \mathrm{Ln}$ or $\mathrm{Fe}_{3} \mathrm{Ln}$ with the lanthanides Gd or Dy [66]. More generally, typical paramagnetic 3d ions used in such complexes are transition metal ions such as $\mathrm{Co}^{\mathrm{II}}, \mathrm{Mn}^{\mathrm{II}}, \mathrm{Mn}^{\mathrm{III}}, \mathrm{Fe}^{\mathrm{II}}, \mathrm{Fe}^{\mathrm{III}}, \mathrm{Ni}^{\mathrm{II}}$, and $\mathrm{Cu}^{\mathrm{II}}$, while $4 \mathrm{f}$ ions can be, e.g., lanthanide ions such as $\mathrm{Dy}{ }^{\mathrm{III}}, \mathrm{Tb}^{\mathrm{III}}$, $\mathrm{Gd}^{\mathrm{III}}$, or $\mathrm{Er}^{\mathrm{III}}$ [67]. Even diamagnetic $3 \mathrm{~d}$ metal ions can sometimes be used to create SMMs [68].

Recently, Zheng et al. investigated the molecules containing heterometallic (FeDy) complexes with the formulas $\mathrm{C}_{50} \mathrm{H}_{100} \mathrm{Dy}_{2} \mathrm{Fe}_{4} \mathrm{~N}_{10} \mathrm{O}_{32}$ and $\mathrm{C}_{40} \mathrm{H}_{76} \mathrm{Dy}_{2} \mathrm{Fe}_{6} \mathrm{~N}_{12} \mathrm{O}_{42}$. The structures of the complexes showed different bonds when the molecules formed a crystal, thus resulting in different stacking patterns and, correspondingly, different temperaturedependent susceptibilities in different DC fields [69].

Hou et al. also investigated Dy compounds, more specifically $\left[\mathrm{Dy}(\mathrm{TTA})_{2} \mathrm{~L}\right]_{2}$ and $\left[\mathrm{Dy}(\mathrm{dbm})_{2} \mathrm{~L}\right]_{2}$ with the $\beta$-diketones TTA (2-thenoyltrifluoroacetone) and dbm (dibenzoylmethane), as well as the Schiff base ligand 2-[(4-chlorophenyl)imino]methyl]-8-hydroxyquinoline. While the structures, as depicted in Figure 3, are similar for both compounds, strongly different susceptibilities were also measured [70].

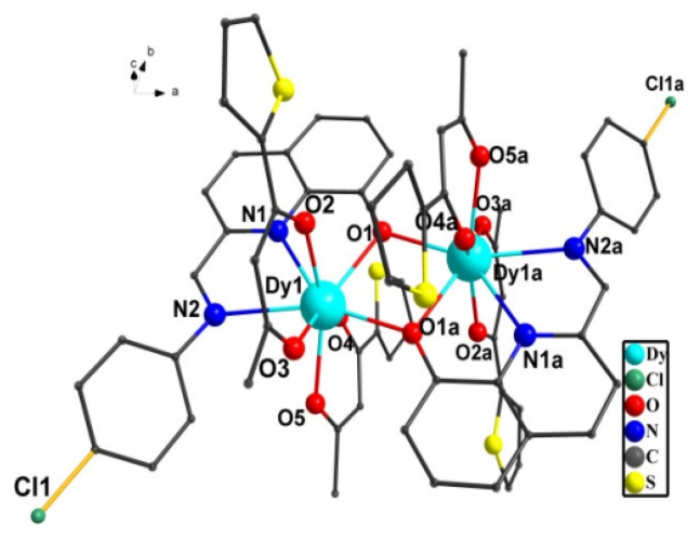

(a)

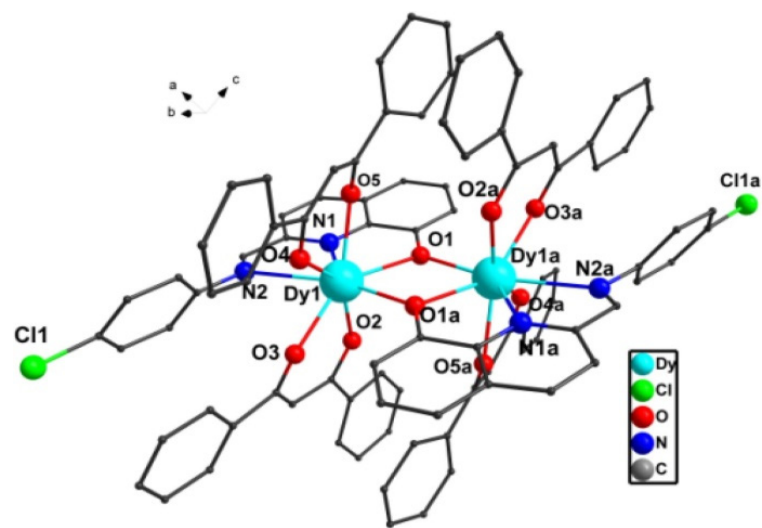

(b)

Figure 3. Molecular structures of $(\mathbf{a})\left[\mathrm{Dy}(\mathrm{TTA})_{2} \mathrm{~L}\right]_{2} ;(\mathbf{b})\left[\mathrm{Dy}(\mathrm{dbm})_{2} \mathrm{~L}\right]_{2}$. Hydrogen atoms are omitted for clarity; abbreviations are given in the main text. Reprinted from [70], copyright 2020, with permission from Elsevier. 
Generally, many researchers have concentrated on the aforementioned 3d-4f metal complexes. Das et al. recently gave an overview of the structural variety of $3 \mathrm{~d}-4 \mathrm{f}$ heterometallic polyoxometalates, including dimers, trimers, and tetramers, and the different polyanions, such as pure $3 \mathrm{~d}-4 \mathrm{f}$ polyanions, $3 \mathrm{~d}$ substituted anions with $4 \mathrm{f}$ linkers, $4 \mathrm{f}$ substituted anions with $3 \mathrm{~d}$ linkers, and polyoxometalates with $3 \mathrm{~d}$ and $4 \mathrm{~d}$ linkers. They concentrated not only on the possibilities of using such $3 \mathrm{~d}-4 \mathrm{f}$ polyoxometalates as singlemolecule or single-ion magnets, but also for applications in catalysis [71].

Wang et al. prepared $3 \mathrm{~d}-4 \mathrm{f}$ clusters with $\mathrm{Co}^{\mathrm{III}}{ }_{2} \mathrm{Dy}^{\mathrm{III}}{ }_{4}$ and $\mathrm{Co}^{\mathrm{III}}{ }_{2} \mathrm{Gd}^{\mathrm{III}}{ }_{4}$, respectively, using chemical reactions and structural $\mathrm{X}$-ray characterization. Their investigations revealed centrosymmetric hexanuclear metallic cores. Interestingly, they found ferromagnetic coupling for the Dy ${ }^{\mathrm{III}}$ ions and antiferromagnetic coupling for the $\mathrm{Gd}^{\mathrm{III}}$ ions, in spite of the othewise identical composition, with the lanthanide ions being coplanar, thus underlining the importance of the choice of the lanthanide [72]. On the other hand, Dy 4 was also reported in similar structures, working as a single-molecule magnet, but with different energy barriers and other physical properties, indicating the importance of the whole molecular structure, even in the case of structures that seemed very similar at first glance [73-75]. In these works, the structural single-crystal X-ray diffraction investigations were additionally supported by dc and ac magnetic susceptibility studies [73].

In tetranuclear 3d-4f systems containing $\mathrm{DyFe}(\mathrm{CN})_{6}, \mathrm{TbFe}(\mathrm{CN})_{6}, \mathrm{HoFe}(\mathrm{CN})_{6}, \mathrm{DyCo}(\mathrm{CN})_{6}$, $\mathrm{TbCo}(\mathrm{CN})_{6}$, or $\mathrm{HoCo}(\mathrm{CN})_{6}$, respectively, Wang et al. also found differences between the isomorphic compounds. Especially, the complex containing $\operatorname{DyFe}(\mathrm{CN})_{6}$ showed a weak antiferromagnetic interaction between $\mathrm{Dy}$ and $\mathrm{Fe}$, and no slow magnetic relaxation above $2 \mathrm{~K}$, which would be typical for an SMM, while this effect was found in the complex containing DyCo $(\mathrm{CN})_{6}$. Wang et al. attributed this finding to a larger intermolecular Dy-Dy distance for the second complex, based on the diamagnetic properties of the $\mathrm{Co}^{\mathrm{III}}$ ion, as opposed to the paramagnetic $\mathrm{Fe}^{\mathrm{III}}$ ion [76]. The authors concluded these results from magnetic susceptibility experiments, including real and imaginary parts, as a function of the temperature within the range of 2-20 K. Many other authors investigated these and other lanthanide-hexacyanidometallate SMMs [77-80].

Lun et al. also investigated $\mathrm{CO}_{\mathrm{OII}}{ }_{2}$ combined with Dy, using structural characterization, in this case in the complex $\left\{\left[\mathrm{Co}^{\mathrm{III}}{ }_{2} \mathrm{Dy}_{3} \mathrm{Na}\left(\mathrm{CH}_{3} \mathrm{CH}_{2} \mathrm{COO}\right)_{6}(\mathrm{OH})_{6}\left(\mathrm{NO}_{3}\right)_{4}\left(\mathrm{H}_{2} \mathrm{O}\right)_{2}\right] \cdot \mathrm{H}_{2} \mathrm{O}\right\}_{n}$. They found a trigonal bipyramidal geometry in the $\mathrm{Co}_{2} \mathrm{Dy}_{3}$ core and a single-molecule magnetic behavior for the whole complex with an energy barrier of $60.3 \mathrm{~K}$ under a zero dc field [81].

$\mathrm{CO}^{\mathrm{II}}$ was investigated by Zhang et al. They prepared 3d-4f heterometallic complexes with $\mathrm{Co}_{2}{ }_{2}-\mathrm{Ln}^{\mathrm{III}}{ }_{2}$ units, applying $\mathrm{Nd}, \mathrm{Sm}, \mathrm{Eu}, \mathrm{Gd}, \mathrm{Tb}, \mathrm{Dy}$, and $\mathrm{Er}$ as the lanthanides. The structures of the complexes containing Er and all of the other lanthanides are depicted in Figure 4. Interestingly, they found, on the one hand, that the molecular structures of all complexes besides the one containing Er were identical, which was attributed to $\mathrm{Er}^{\mathrm{III}}$ being smaller than Dy ${ }^{\mathrm{III}}$. On the other hand, a weak ferromagnetic interaction between the metal ions was found for Gd and Er, while the complex containing Dy again showed field-induced slow magnetic relaxation, typical for SMMs [82]. 


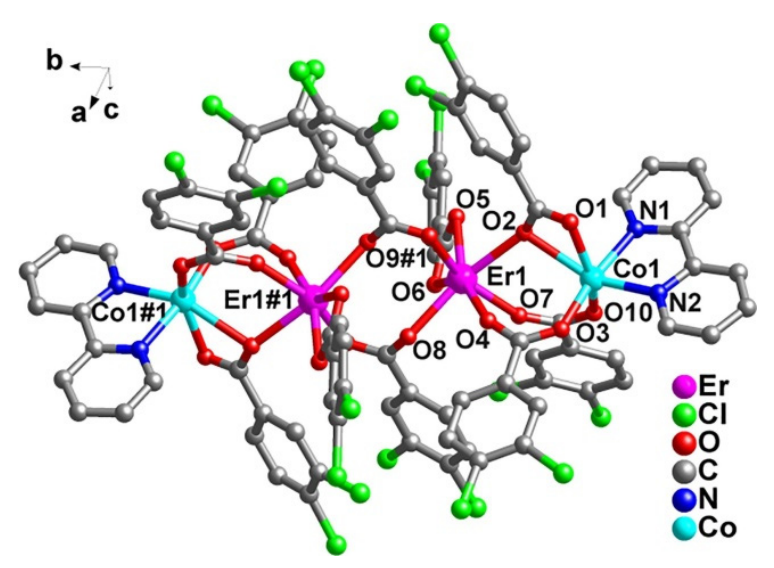

(a)

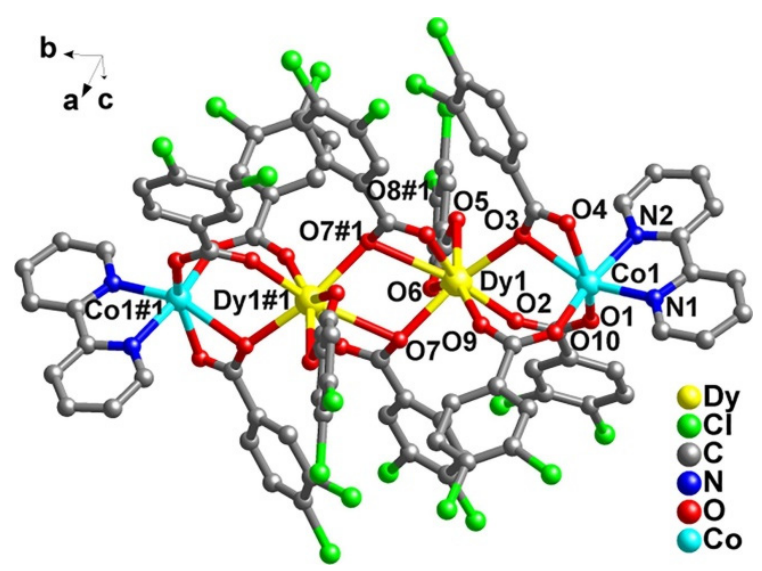

(b)

Figure 4. Molecular structures of the complexes containing (a) $\mathrm{Co}_{2}{ }_{2}-\mathrm{Er}^{\mathrm{III}}{ }_{2}$ and (b) $\mathrm{Co}_{2}{ }_{2}-\mathrm{Ln}^{\mathrm{III}}{ }_{2}$. Hydrogen atoms are omitted for clarity. Reprinted from [82], copyright 2020, with permission from Elsevier.

Xi et al. also worked with $\mathrm{Co}^{\mathrm{II}}$, in the form of $\mathrm{Co}^{\mathrm{II}}-\mathrm{Ln}^{\mathrm{III}}$ with the lanthanides $\mathrm{Y}, \mathrm{Gd}, \mathrm{Tb}$, Dy, and Ho, and found SMM behavior for the combination with Dy [83]. In these studies, the magnetic susceptibility method was complemented with fluorescence spectroscopy, revealing the characteristic energy levels of the $\mathrm{Tb}$ ions.

Again, another metal, $\mathrm{Cr}$, was used by $\mathrm{Yu}$ et al. in different coordination polymers with the basic units of $\mathrm{Gd}_{4} \mathrm{Cr}_{4}, \mathrm{~Tb}_{4} \mathrm{Cr}_{4}$, or $\mathrm{Er}_{4} \mathrm{Cr}_{4}$. They found a butterfly-like structure of the basic unit and each basic unit was connected with four $\mathrm{Ln}_{4} \mathrm{Cr}_{4}$ clusters in a 3D structure resembling a 1D honeycomb [84]. Apart from standard single-crystal X-ray diffractometry and magnetic susceptibility studies, they employed isothermal thermogravimetry/differential thermal analysis (TG/DTA) experiments to detect the magnetic entropy changes.

With $\mathrm{Zn}$ as the metal and Dy, Tb, or Er as the lanthanide, Fan et al. prepared heterometallic complexes with a windmill-like structure and a $\left(\operatorname{Ln}_{3} \mathrm{Zn}_{3}\right)$ core. They found fieldinduced frequency-dependent signals, measured by field-induced frequency-dependent signals, as a sign of SMM behavior for Dy and Tb, while the Er-based complex showed a slow magnetic relaxation [85].

$\mathrm{Cu}$ was combined with $\mathrm{Dy}, \mathrm{Tb}$, and $\mathrm{Gd}$ to prepare the tetranuclear $\mathrm{Cu}_{2}{ }_{2} \mathrm{Ln}_{2}{ }_{2}$ complexes. These complexes were isostructural and isomorphic, and showed ferromagnetic interactions between $\mathrm{Cu}^{\mathrm{II}}$ and $\mathrm{Ln}^{\mathrm{III}}$ in all cases, as well as SMM behavior, with $\mathrm{Cu}^{\mathrm{II}} \mathrm{Gd}^{\mathrm{III}}$ exhibiting a magneto-caloric effect [86].

Quite a different approach was recently chosen by Darii et al., who combined $\mathrm{Mn}_{6}$ clusters with $\mathrm{Dy}{ }^{\mathrm{III}}$ and a triazine-like ligand to create a large bean-shaped cluster $\left[\mathrm{Mn}_{26} \mathrm{Dy}_{6} \mathrm{O}_{16}\right.$ $(\mathrm{OH})_{12}\left(\mathrm{O}_{2} \mathrm{CCHMe}_{2}\right)_{42}$ with $\mathrm{Mn}^{\mathrm{II}}, \mathrm{Mn}^{\mathrm{III}}$, and Dy ${ }^{\mathrm{III}}$ ions, in this way enabling diverse magnetic interactions and leading to a high-nuclearity Mn-Dy cluster that still exhibits an SMM behavior [87].

Multi-decker systems of lanthanides with phthalocyanine molecules have been described by different groups. Gao et al. prepared sandwich-like complexes based on phthalocyanine molecules and a closed-macrocyclic Schiff base of the form $\left[(\mathrm{Pc})_{2} \mathrm{Ln}_{3}(\mathrm{~L})(\mathrm{OAc})\left(\mathrm{OCH}_{3}\right)_{2}\right]$ (with $\mathrm{Ln}^{3+}=\mathrm{Dy}^{3+}$ or $\mathrm{Er}^{3+}, \mathrm{H}_{2} \mathrm{Pc}=$ phthalocyanine and $\mathrm{H}_{2} \mathrm{~L}=$ closed-macrocyclic Schiff base molecules), and found a single-molecule magnetic behavior in the complex containing dysprosium [88]. In these sandwich structures, the strong coupling between the lanthanide ions resulted in an important role for the rare earth atom in the SMM properties [89], making these multi-decker structures highly interesting for diverse applications [90-92].

Going one step further, Patrascu et al. prepared coordination compounds with three different spin carriers ( $2 \mathrm{p}$, in addition to $3 \mathrm{~d}$ and $4 \mathrm{f}$ ), resulting in three different exchange interactions between each pair of spin carriers. By adding a $2 \mathrm{p}$ radical (Rad) to gain a three-dimensional Co ${ }^{\mathrm{II}} \mathrm{Dy}{ }^{\mathrm{III}}$ Rad derivative, they reached slow relaxation below $30 \mathrm{~K}$ and 
attributed the improved magnetic properties mainly to the $\mathrm{Co}^{\mathrm{II}}$-Rad interaction [93], while $\mathrm{Zn}^{\mathrm{II}} \mathrm{Dy}{ }^{\mathrm{III}} \mathrm{Rad}$ showed a significantly lower energy barrier and the linear $\mathrm{Co}^{\mathrm{II}} \mathrm{Dy}{ }^{\mathrm{III}} \mathrm{Rad}$ compound showed no SMM behavior at all [94]. A broad overview of the possible metal centers for single-molecule and single-ion magnets, from $3 \mathrm{~d}$ and $5 \mathrm{~d}$ to $4 \mathrm{f}$ and $5 \mathrm{f}$, is given in a recent review by Feng and Tong [95].

Lunghi et al. performed theoretical investigations that examined the under-barrier relaxation at high temperatures, which prohibited the use of SMMs at room temperature [96]. While anharmonic phonons were found to be responsible for the previously mentioned effect, spin-phonon coupling led to spin relaxation in the prototypical mononuclear SMM $\left[\left(\mathrm{tpa}^{\mathrm{Ph}}\right) \mathrm{Fe}\right]^{-}[97,98]$. Ab initio calculations of single-molecule magnets have been performed by Vonci et al. [99] and Gransbury et al. [100].

For spin-based devices based on SMMs, controlling the spin relaxation is of the utmost importance. Sorensen et al. reported on the effect of a non-linear to pseudo-linear change in the crystal field symmetry in a dysprosium complex, leaving the residual chemistry unaltered, and found a strong reduction in the tunnel splitting at very low temperatures in the milliKelvin range [101]. Switching the magnetic anisotropy reversibly was enabled in lanthanide complexes as a function of external magnetic field and temperature [102,103].

Redox-active tetrathiafulvalene (TTF)-based ligands, on the other hand, allowed for designing coordination lanthanide complexes in different oxidation states, resulting in different magnetic properties for such SMMs [104]. An overview of such TTF-based ligands is given in [105].

Another important parameter for future applications is spin relaxation barriers. In particular, high spin-reversal barriers of $413 \mathrm{~cm}^{-1}$ [106] and $450 \mathrm{~cm}^{-1}$ [107] were measured in the approximately linear $\mathrm{Co}^{\mathrm{II}}$ complexes $(\mathrm{sIPr}) \mathrm{CoNDmp}$ (with $\mathrm{sIPr}=\mathrm{N}$-heterocyclic carbene and $\mathrm{NDmp}=$ arylimido ligand $)$ and $\mathrm{Co}\left(\mathrm{C}\left(\mathrm{SiMe}_{2} \mathrm{ONaph}\right)_{3}\right)_{2}$ (with $\mathrm{Me}=$ methyl and Naph = naphthyl group), respectively.

\section{Single-Chain Magnets}

Single-chain magnets (SCMs) have been investigated since the early 2000s [108-112]. Similar to SMMs, they show a magnetic hysteresis loop and slow relaxation of the magnetization at low temperatures [113]. It should be mentioned, however, that the slow relaxation dynamics in SCMs are different from the quantum tunneling found in SMMs; here, there are spins in the chain flip, a process that may propagate and even result in collective reversal of short chains [113]. In this regard, SCMs are much closer to purely inorganic magnetic nanowires or nanostrips, as mentioned in the introduction.

A systematic overview of the possible strategies to prepare such SCMs was given in 2010 by Sun et al. (Figure 5) [22]. While the ferromagnetic spin arrangement is not often found because of the complex dipole-dipole interactions in the chain, it can still be found in different spin structures, ferromagnetically coupling anisotropic spin carriers. The ferrimagnetic spin state is often more stable, and the first reported SCM also showed ferrimagnetic coupling. Spin-canted chains show a weak ferromagnetic order, and SCMs based on this principle are not often observed [22]. In this simple approach, interchain interactions, chirality, photo-switchable states or other highly interesting possibilities, have not yet been taken into account [114].

\section{(1) Ferromagnetic-chain strategy $\longrightarrow 1,11111$}

\section{(2) Ferrimagnetic-chain strategy}

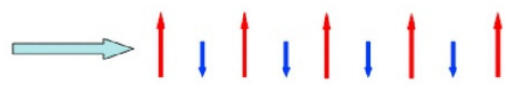

\section{(3) Spin-canted-chain strategy}

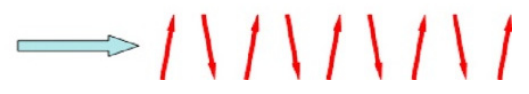

Figure 5. Possible strategies for single-chain magnets. Reprinted from [22], copyright 2010, with permission from Wiley. 
Nowadays, research on SCMs is, on the one hand, still focused on fully understanding the theoretical basics, and, on the other hand, practical, application-related interests such as high blocking temperatures and very slow relaxation are also being investigated.

Two magnetic phase transitions were found by Nadeem et al. in a $\mathrm{Ni}_{4} \mathrm{O}_{4}$-cubanebased network of $1 \mathrm{D}$ linear chains of $\mathrm{Ni}^{\mathrm{II}}$ ions, crosslinked via $\mathrm{Ni}_{4} \mathrm{O}_{4}$ cubanes. While magnetic ordering occurred below $23.9 \mathrm{~K}$, a structural phase transition was recognized at $2.8 \mathrm{~K}$ through the use of susceptibility measurements [115].

Another interesting feature was reported by Liu et al. for $\mathrm{Co}^{\mathrm{II}}$ chains. In the singlechain magnets of $\mathrm{Co}(\mathrm{hfac})_{2}(\mathrm{R}-\mathrm{NapNIT})$ with R-NapNIT $=2-\left(2^{\prime}-(\mathrm{R}-)\right.$ naphthyl)-4,4,5,5-tetram ethylimidazoline-1-oxyl-3-oxide and $\mathrm{R}=\mathrm{MeO}$ or EtO, very large coercive fields were found at low temperatures, i.e., $62 \mathrm{kOe}$ and $65 \mathrm{kOe}$ for both compounds, respectively [116]. The research group used static and pulsed high-intensity magnetic fields to obtain these results.

Yang et al. prepared azido-bridged homospin coordination polymers based on $\mathrm{Fe}^{\mathrm{II}}$ and $\mathrm{Co}^{\mathrm{II}}$, more specifically $\left[\mathrm{Fe}_{2}(\mathrm{Bzp})_{2}\left(\mathrm{~N}_{3}\right)_{4}\right]_{n}$ and $\left[\mathrm{Co}_{4}(\mathrm{Bzp})_{4}\left(\mathrm{~N}_{3}\right)_{8} \cdot(\mathrm{MeOH})_{2}\right]_{n}$, respectively, with bzp $=2$-benzoylpyridine, forming neutral chains with azido-bridges. They found ferromagnetic intrachain interactions in both SCMs and broad hysteresis loops [117]. Cyanobridges were used to prepare a $\left[\mathrm{Mo}(\mathrm{CN})_{7}\right]^{4-}$ based SCM in which the magnetic anisotropy stemmed from the anisotropic magnetic exchange of the cyanide ligands of the $\mathrm{Mo}^{\mathrm{III}}$ units and the $\mathrm{Mn}^{\mathrm{II}}$ spins, resulting in relatively high blocking temperature and large coercive fields of up to $15 \mathrm{kOe}$ [118]. Jiang et al. also used cyanide bridges in an $\mathrm{Fe}_{2} \mathrm{Co}$ 4,2-ribbon single-chain magnet [119]. Several other studies on cyanide-bridged SCMs have been performed by Ohkoshi and Sieklucka with their groups [120-122], as well as by other research groups [123-125].

Other lanthanides may also offer interesting SCM properties. Yang et al. prepared $\left[\mathrm{LnCu}(\mathrm{hfac})_{5} \mathrm{NIT}-\mathrm{Ph}-\mathrm{p}-\mathrm{OCH}_{2} \text { trz-0.5 } \mathrm{C}_{6} \mathrm{H}_{14}\right]_{\mathrm{n}}$ with $\mathrm{Ln}=\mathrm{Er}, \mathrm{Ho}, \mathrm{Yb}$, resulting in ladder-like chain structures, as depicted in Figure 6 for the case of Er. Here, inserting Ho into the complex resulted in single-chain magnet behavior, as indicated by the frequency-dependent out-of-phase AC magnetic susceptibility [126].

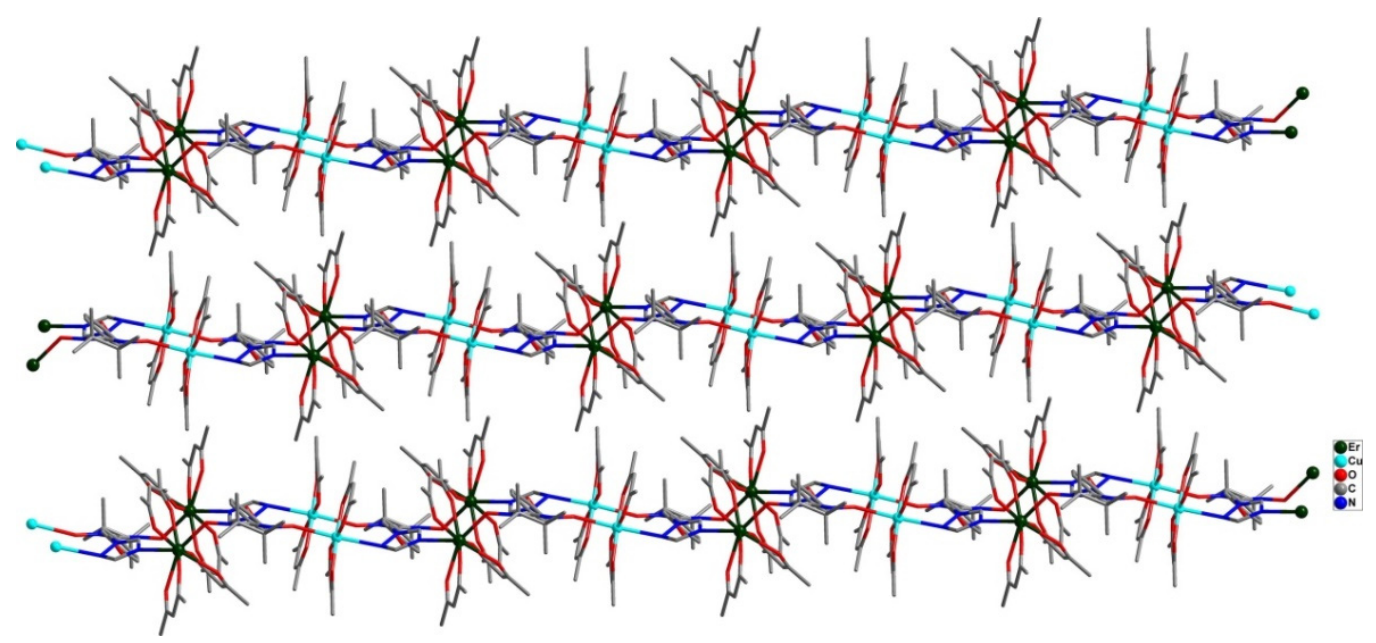

Figure 6. Crystal packing of $\left[\mathrm{ErCu}(\mathrm{hfac})_{5} \mathrm{NIT}-\mathrm{Ph}-\mathrm{p}-\mathrm{OCH}_{2} \mathrm{trz} \cdot 0.5 \mathrm{C}_{6} \mathrm{H}_{14}\right]_{\mathrm{n}}$ chains. Reprinted from [126], copyright 2020, with permission from Elsevier.

In the so-called "butterfly molecule" $\left[\mathrm{Fe}_{3} \mathrm{Y}(\mu 3-\mathrm{O})_{2}\left(\mathrm{CCl}_{3} \mathrm{COO}\right)_{8}\left(\mathrm{H}_{2} \mathrm{O}\right)(\mathrm{THF})_{3}\right]$, the $\mathrm{Fe}^{3+}$ ions form an $\mathrm{Fe}_{3}$ cluster with a strong intracluster exchange and a $S=5 / 2$ total spin without long-range magnetic ordering down to $20 \mathrm{mK}$. At low temperatures, a quantum tunneling process was revealed, as is usual in SMMs, and this single-chain magnet was described as combining single-molecule magnetic anisotropy with a spin-spin correlation along the chains [127].

Single-chain magnet behavior was also observed, using powder $\mathrm{X}$-ray diffraction, for the $\mathrm{Cu}-\mathrm{Tb}$ chain complexes $\left[\mathrm{TbCu}(\mathrm{hfac})_{5} \mathrm{NIT}-\mathrm{Ph}-\mathrm{p}-\mathrm{OCH}_{2} \text { trz } \cdot 0.5 \mathrm{C}_{6} \mathrm{H}_{14}\right]_{\mathrm{n}}$ and $\left[\mathrm{LnCu}(\mathrm{hfac})_{5} \mathrm{NIT}-\right.$ 
$\mathrm{Ph}-\mathrm{p}-\mathrm{OCH}_{2}$ trz $]_{n}$ with NIT-Ph- $p-\mathrm{OCH}_{2}$ trz $=2-(4-((1 \mathrm{H}-1,2,4$-triazol-1-yl)methoxy $)$ phenyl $)-$ 4,4,5,5-tetramethylimidazoline-1-oxyl-3-oxide and $\mathrm{hfac}=$ hexafluoroacetylacetonate. While the first complex shows a ladder-chain structure, the second one forms a linear chain. Both of these $2 \mathrm{p}-3 \mathrm{~d}-4 \mathrm{f}$ heterotrispin systems made of chains from nitronyl-nitroxide show a single-chain magnet behavior with a slow magnetic relaxation below $3 \mathrm{~K}$ [128].

Another shape of the chain was found by Houard et al. in nitronyl-nitroxide organic radical chains. In $\left[\mathrm{Tb}(\mathrm{hfac})_{3} \mathrm{NIT-O}-\mathrm{Hexyl}\right]_{n}$ latter structures, with $\mathrm{hfac}^{-}=$hexafluotoacetylacetonate, chiral curled chains were formed, building supramolecular tubes with a diameter of $4.5 \mathrm{~nm}$ and large coercive fields, as visible in Figure 7 [129].
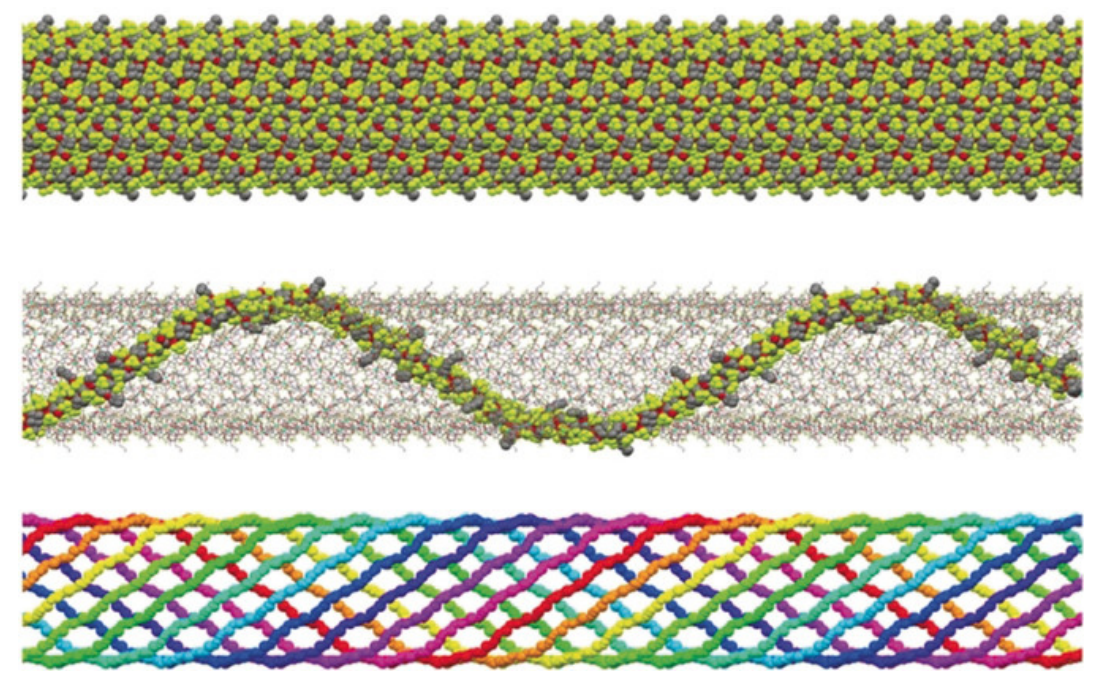

Figure 7. The supramolecular nanotube formed by $\left[\mathrm{Tb}(\mathrm{hfac})_{3} \mathrm{NIT}-\mathrm{O}-\mathrm{Hexyl}\right]_{n}$ chains, showing (top) all atoms; (middle) one chain; (bottom) magnetic backbones only of 11 curled chains forming one nanotube. Reprinted from [129], copyright 2020, with permission from Wiley.

Zhang et al. found slow relaxation and the typical temperature-dependent out-ofphase AC magnetic susceptibility pointing out SCM behavior in the chain complexes $\left.\left[\mathrm{Mn}_{2} \text { (salen }\right)_{2}(\mathrm{~L})\right]\left(\mathrm{ClO}_{4}\right)$ and $\left\{[\mathrm{Mn}(\text { salen })]_{2}(\mathrm{~L})_{2}\right\} \cdot Y$, with salen $=N, N^{\prime}$-bis(salicylidene)-ethylen ediamine, $\mathrm{L}=3,4,5$-trifluorobenzeneseleninic acid, and $\mathrm{Y}=$ salicylaldehyde, which is unusual for aromatic selenite-based materials [130].

Another unusual SCM was produced by Zhao et al. who prepared homospin $\mathrm{Co}^{\mathrm{II}}$ ferrimagnetic SCMs in the form of $\left[\mathrm{Co}_{3}(\mathrm{~L})_{4}(\mathrm{OH})_{2}\left(\mathrm{H}_{2} \mathrm{O}\right)_{2}\right]_{n}$ with $\mathrm{L}=4$-(tetrazol-5-yl)phenyl$4,2^{\prime}: 6^{\prime}, 4^{\prime \prime}$-terpyridine). These 1D chains exhibited triangular non-uniform chains, bridged by ligands to form a 2D coordination framework. This system showed an SCM behavior with large hysteresis loops and activation energies varying for infinite- or finite-chain regimes [131]. $\mathrm{Co}^{\mathrm{II}}$ ions were also included in the $1 \mathrm{D}$ coordination polymer $\left[\left\{\mathrm{Co}_{2}(\mathrm{pymca})_{2}\right.\right.$. $\left.\left.\left(\mathrm{H}_{2} \mathrm{O}\right)_{4}\right\} \mathrm{SO}_{4} \cdot 2 \mathrm{H}_{2} \mathrm{O}\right]_{\mathrm{n}}$ with pymca $=2$-carboxypyrimidine, which showed an SCM behavior below $3 \mathrm{~K}$ [132], and in $\mathrm{Co}^{\mathrm{II}}$ metal-organic frameworks with a strong magnetic 1D anisotropy, applying different bridging ligands [133].

Besides the aforementioned examples, many other variations of SCMs can be found in the recent literature, based on diverse physical principles, combining a broad variety of materials and shapes. Here, as well as in SMMs, many more highly interesting new findings can be expected in the next years.

\section{Theoretical Aspects and Methods}

Besides the aforementioned theoretical aspects in the evaluation of new materials and understanding of the measured phenomena, here, a brief overview is given on the recent theoretical aspects and methods used to model molecular magnets.

One of the most interesting problems in molecular magnets is decoherence. Takahashi et al. investigated environmental decoherence and showed that the theory for 
insulating electronic spin systems could predict environmental decoherence in molecular quantum magnets well, based on phonons, nuclear spins, and intermolecular dipolar interactions [134]. The theory of environmental decoherence was experimentally first verified in the $\mathrm{Fe}_{8}$ complex by spin-echo measurements and was compared with calculations from the Hamiltonian model used to predict the field splitting [134]. Decoherence is highly important as it modifies the equations describing the time-dependent evolution of a magnetic moment in a varying magnetic field, i.e., the Landau-Zener expression, which allows for calculating the spin reversal probability in a constantly swept magnetic field $[135,136]$. The equation is limited to time scales much smaller than the dephasing time, as pointed out for a single-molecule spin transistor containing the single-ion magnetic molecule $\mathrm{TbPc}_{2}$ (with $\mathrm{Pc}=$ phthalocyanine), by comparing the experimental results with calculations based on a Hamiltonion description of the interplay between the time-dependent magnetic field and a constant tunneling term [137]. Mirzoyan and Hadt used density functional theory (DFT) and time-dependent DFT to calculate decoherence due to spin-phonon coupling in spin $\frac{1}{2}$ transition molecular qubits based on $\mathrm{Cu}(\mathrm{II})$ and $\mathrm{V}(\mathrm{IV})$, using the ORCA program to generalize the ligand field theory (LFT) and to enable a comparison of the experimental results with those of LFT, DFT, and time-dependent DFT [138]. A broad overview of such DFT calculations used for SMMs was given by Postnikov et al., who reported on recent interesting systems based on $\mathrm{Ni}_{4}, \mathrm{Co}_{4}, \mathrm{Fe}_{4}, \mathrm{Mn}_{10}$ clusters, and $\mathrm{V}_{15}$, and discussed the anisotropies in different single-molecule magnets [139]. Taran et al. recently showed that a phenomenological Lindblad operator was suitable to model spin-flip probability for small probing currents for different temperatures, cooling times, and sweeping rates in a diluted crystal of $\mathrm{TbPc}_{2}$ lanthanide single ion molecular magnets [140]. Spin dephasing was studied by propagation of unitary quantum spin dynamics in a reduced Hilbert space to model spin dephasing in vanadyl-based molecular qubits $\mathrm{VO}(\mathrm{acac})_{2}$ and $\mathrm{VO}(\mathrm{dmit})_{2}$ ( with acac $=$ acetylacetonate and $\mathrm{dmit}=1,3$-dithiole-2-thione-4,5-dithiolate), applying ORCA to compute some not experimentally available parameters [141]. Hu et al. used the Kubo-Anderson model to connect hyperfine coupling, calculated using DFT, to the coherence time for different vanadyl complexes [142]. It should be mentioned that besides environmental decoherence, there is also an intrinsic decoherence, which is actually a breakdown of quantum mechanics and is much harder to understand [143].

Besides the aforementioned problem of decoherence or coherence time, several more specific questions have risen with respect to molecular magnets and were solved by different theoretical approaches. Liu et al., e.g., used an analytical theory to correlate the tunnel splitting of a single molecular spin with the height of the quantum steps found in the hysteresis loops of the molecular magnets $\mathrm{Fe}_{8}, \mathrm{Mn}_{12}$, and $\mathrm{Mn}_{4}$ [144]. Bhandary et al. combined DFT using the VASP code with second order perturbation theory to calculate a strain-induced spin change in iron porphyrin embedded in a graphene lattice [145]. Baker et al. used DFT calculations to model different types of magnetic frustration in molecular magnets containing homometallic $\{\mathrm{Cr} 9\}$ rings [146]. Abufager et al. also used DFT calculations by combining VASP, SIESTA, and TRANSIESTA to describe the spinfiltering capacities of the metallo-organic molecule $\mathrm{CoFeCp}_{3}$ (with $\mathrm{Cp}=$ cyclopentadienyl) for tunneling, as well as in cases of direct contact [147]. Vieru et al., however, used ab-initio calculations of Molcas 8.0 combined with SINGLE ANISO and POLY ANISO to understand magnetization blocking in $\mathrm{Fe}_{2}{ }^{\mathrm{III}} \mathrm{Dy}_{2}{ }^{\mathrm{III}}$ molecular magnets, or, more exactly, $\left[\mathrm{Fe}_{2} \mathrm{Dy}_{2}(\mathrm{OH})_{2}(\text { teaH })_{2}\left(\mathrm{RC}_{6} \mathrm{H}_{4} \mathrm{COO}\right)_{6}\right]$ complexes, with teaH $\mathrm{H}_{3}=$ triethanolamine and $\mathrm{R}=$ meta- $\mathrm{CN}$, para- $\mathrm{CN}$, meta- $\mathrm{CH}_{3}$, para- $\mathrm{NO}_{2}$, and para- $\mathrm{CH}_{3}$ [148]. Besides the aforementioned modules, post-Hartree-Fock ab-initio calculations are nowadays often performed with the modules CASSCF (complete active space self-consistent field), RASSI, and SINGLEANISO [99,149-152].

Finally, it should be mentioned that several open-source software solutions are available to calculate the magnetic properties of SMMs and SCMs. Mannini et al. [153], e.g., report on using NWChem, an open-source solution for large-scale molecular simulations that is well suited for magnetic systems [154]. Prsa et al. [155] used Monte Carlo simulations 
with the ALPS framework [156] to investigate lanthanide-based SMMs. The same software was used by Baniodeh et al. [157]. Another one is CP2K [158], a software used to calculate molecular dynamics, which was used, e.g., by Burgess et al. [159]. Tandon et al. most recently introduced J2suscep to calculate the magnetism of molecular complexes [160], while Smith et al. reported on the open-source ab-initio electronic structure program PSI4 [161], and Pronk et al. presented the open source molecular simulation toolkit GROMACS [162].

As this short overview shows, most problems are theoretically investigated by DFT calculations, while there are several additional theoretical approaches used in combination with DFT or solely to understand the special experimental findings.

\section{Potential Challenges in the Application of Molecular Nanomagnets}

The application of molecular magnets means bringing them into an environment with which they can interact via their ligands. In case of using molecular nanomagnets, e.g., as magnetic labels for biosensing or as hyperthermia agents, self-assembling of clusters or chains cannot be excluded under the application of an external magnetic field, which would change magnetic states and magnetization dynamics compared with single molecular nanomagnets. Aggregates may be formed by magnetizable nanoparticles depending on their biological environment, mimicking the surrounding natural tissue properties. Such sometimes desired, sometimes unrequested processes are known from magnetic gels [163-165] and have to be taken into account during the development of modern compact medical devices based on molecular nanomagnets [166-168].

As Domingo et al. pointed out in their review [166], SMMs forming self-assembled monolayers on surfaces show different magnetic properties, particularly different anisotropies and anisotropy axes, compared with the single SMMs that are often theoretically investigated. They describe different studies aimed at orienting the easy magnetization axis of SMM clusters on surfaces, either by self-organization or by partial functionalization through ligand substitution with binding surface groups. This means, on the other hand, that the ligand shell defines the orientation of SMMs on surfaces or during self-assembly in biomedical applications [169], so that this parameter has to be taken into account to reach the desired magnetic properties and to avoid possible interference effects between neighboring SMMs in such a cluster, as compared with single SMMs.

\section{Recent Trends in Molecular Nanomagnets}

Besides the aforementioned topics, which are often related to basic research, some recent trends should be mentioned that are currently in the focus of research in this area, often aiming at multifunctional molecular magnets.

One of these topics is related to luminescent SMMs based on lanthanides for possible application in quantum computing, bio-labeling, or LEDs. Jia et al. recently reviewed the design strategies for such luminescent lanthanide-based SMMs, pointing out the necessary combination of a strongly UV absorbing ligand environment that efficiently populates excited states in the metal ion, with a filled-up coordination sphere of the Ln(III) ions to reduce radiation-less deactivation processes [170]. Yi et al. investigated the isostructural dimers $\left[\mathrm{Ln}(\mathrm{hfac})_{3}(\mathrm{PyNO})\right]_{2}$ (with the lanthanides $\mathrm{Eu}, \mathrm{Gd}, \mathrm{Tb}$, and Dy) and found luminescence for $\mathrm{Eu}, \mathrm{Tb}$, and $\mathrm{Dy}$ [171]. For $\mathrm{Yb}^{\mathrm{III}}, \mathrm{Er}^{\mathrm{III}}$, and $\mathrm{Eu}^{\mathrm{III}}$, Jiménez et al. found luminescence in different mononuclear $\mathrm{Ln}^{\mathrm{III}}$ complexes [172]. Wang et al. suggested using a near-infrared emissive SMM as a highly sensitive luminescent thermometer [173]. A review of luminescent Schiff-base lanthanide SMMs can be found in [174].

Other authors have concentrated on the electric properties of SMMs. Long et al. investigated the magneto-electric coupling in a paramagnetic ferroelectric lanthanide complex and found a strong interaction between both electric and magnetic properties, making this material possibly useful for data storage or spintronics applications [175]. The electro-conductive properties of a Dy(III) double-decker SMM were investigated by Sato et al. and Katoh et al. who found conductivity at temperatures below the spin blocking 
temperature and magneto-resistance in the form of a magnetic hysteresis curve, possibly enabling the utilization of such systems as spin valves [176].

Even ferroelectricity was found in SMMs $[177,178]$ and SCMs $[179,180]$.

As this short overview shows, multifunctional molecular nanomagnets enable combining magnetic with different optical or electrical properties, making them highly useful for diverse recent applications.

\section{Reviews on Special Sub-Topics}

While this review gives an overview of the most recent results in the research on molecular nanomagnets, including SCMs and SMMs, diverse reviews on sub-topics can be found in the literature. For a deeper understanding and further reading, here, we give an overview of some recently published reviews.

Slota and Bogani evaluated how SMMs can be used in molecular spintronics and provided a possibility to combine quantum transport with paramagnetic spectroscopy [181] Spin dynamics in SMMs were reviewed by Aravena and Ruiz, focusing on theoretical calculations of the spin relaxation [182].

Zhu et al. concentrated on lanthanide ions in SMMs and the effects of different external stimuli, leading to structural transformations and thus magnetic relaxation [183]. Similarly, Kalita et al. reviewed SMMs based on lanthanide complexes, concentrating on two-coordinate and pentagonal bipyramidal Ln(III) complexes [184]. Tian and Zheng reviewed molecular wheels containing lanthanides [185]. Chorazy et al., on the other hand, reviewed octacyanidometallates, not only in terms of their applications as molecular magnets, but also in terms of further functionalities, making them suitable as magnetic coolers, photomagnets, ionic conductors, etc. [186]. Guan et al. reviewed SMMs based on metallo-fullerenes [187]. Cyanido-bridged coordination polymers were the focus of a recent review of Reczynski et al., in particular dealing with the possibilities of tuning the optical properties of the corresponding SMMs [188]. Coronado concentrated on metal-organic frameworks and 2D materials in molecular magnetism [189]. The special field of molecular transistors in which SMMs can be used was reviewed by Hao et al. [190].

Shao and Wang gave a relatively broad overview of high-performance SMMs, from a basic understanding of the principles until recent research from a chemical perspective [51]. Similarly, Perlepe et al. concentrated on the chemistry of different ligands, but without offering prior basic knowledge [191].

\section{Conclusions}

A review of the most recent developments in single-molecule magnets and singlechain magnets reveals the broad range of the different materials, binding mechanisms, molecular or chain structures, etc., of these classes of molecular nanomagnets, suggesting new findings in the basic research and understanding of the principles of magnetism in these systems. While common inorganic magnets are still better understood than molecular magnets, the latter propose a large field of possible applications that may be enabled by their strongly varying physical properties.

Future directions of research should, on the one hand, aim at investigating more molecular systems in theory and experiments, to develop new SMMs and SCMs with high anisotropy barriers, blocking magnetization reversal, and hysteretic behavior at temperatures higher than room temperature, so as to enable practical utilization in data storage and other applications. On the other hand, the aforementioned multifunctional molecular magnets belong to recent trends that offer even more applications, some of which may not have been taken into account yet.

In general, taking into account the studies published over the last few decades, there is no simpler way to reach these goals than by carefully investigating the parameters of the well-known and newly developed SMMs and SCMs, so as to iteratively improve the desired properties. 
We hope that this overview of some of the typical, as well as a few highly special, properties of SMMs and SCMs will inspire more researchers to investigate this fascinating class of materials.

Author Contributions: Conceptualization, T.B. and A.E.; writing—original draft preparation, A.E. and T.B.; writing-review and editing, both authors; visualization, both authors. Both authors have read and agreed to the published version of the manuscript.

Funding: This research received no external funding.

Institutional Review Board Statement: Not applicable.

Informed Consent Statement: Not applicable.

Data Availability Statement: No new data were created in this review paper.

Conflicts of Interest: The authors declare no conflict of interest.

\section{References}

1. Ding, J.; Adeyeye, A.O. $\mathrm{Ni}_{80} \mathrm{Fe}_{20} / \mathrm{Ni}$ binary nanomagnets for logic applications. Appl. Phys. Lett. 2012, 101, 103117. [CrossRef]

2. McGuigan, M.; Davenport, J.W.; Glimm, J. Computational approach to finite size and shape effects in iron nanomagnets. J. Magn. Magn. Mater. 2008, 320, 190-196. [CrossRef]

3. Sharma, N.; van Mourik, R.A.; Yin, Y.; Koopmans, B.; Parkin, S.S.P. Focused-electron-beam-induced-deposited cobalt nanopillars for nanomagnetic logic. Nanotechnology 2016, 27, 165301. [CrossRef] [PubMed]

4. Morais, P.C.; Lima, E.C.D.; Rabelo, D.; Reis, A.C.; Pelegrini, F. Magnetic resonance of magnetite nanoparticles dispersed in mesoporous copolymer matrix. IEEE Trans. Magn. 2000, 36, 3038-3040. [CrossRef]

5. Chatterjee, B.K.; Ghosh, C.K.; Chattopadhyay, K.K. Temperature depencence of magnetization and anisotropy in uniaxial $\mathrm{NiFe}_{2} \mathrm{O}_{4}$ nanomagnets: Deviations from the Callen-Callen power law. J. Appl. Phys. 2014, 116, 153904. [CrossRef]

6. Ehrmann, A.; Blachowicz, T. Vortex and double-vortex nucleation during magnetization reversal in Fe nanodots of different dimensions. J. Magn. Magn. Mater. 2019, 475, 727-733. [CrossRef]

7. Ehrmann, A.; Blachowicz, T. Systematic study of magnetization reversal in square Fe nanodots of varying dimensions in different orientations. Hyperfine Interact. 2018, 239, 8. [CrossRef]

8. Parkin, S.S.P.; Hayashi, M.; Thomas, L. Magnetic domain-wall racetrack memory. Science 2008, 320, 190-194. [CrossRef]

9. Blachowicz, T.; Ehrmann, A. Magnetization reversal in bent nanofibers of different cross-sections. J. Appl. Phys. 2018, 124, 152112. [CrossRef]

10. Kumar, D.; Jin, T.L.; Risi, S.A.; Sbiaa, R.; Lew, W.S.; Piramanayagam, S.N. Domain wall motion control for racetrack memory applications. IEEE Trans. Magn. 2019, 55, 2300708. [CrossRef]

11. Keller, L.; Al Mamoori, M.K.I.; Pieper, J.; Gspan, C.; Stockem, I.; Schröder, I.; Barth, S.; Winkler, R.; Plank, H.; Pohlit, M.; et al. Direct-write of free-form building blocks for artificial magnetic 3D lattices. Sci. Rep. 2018, 8, 6160. [CrossRef]

12. Kern, P.; Döpke, C.; Blachowicz, T.; Steblinski, P.; Ehrmann, A. Magnetization reversal in ferromagnetic Fibonacci nano-spirals. J. Magn. Magn. Mater. 2019, 484, 37-41. [CrossRef]

13. Al Mamoori, M.; Schröder, C.; Keller, L.; Huth, M.; Müller, J. First-order reversal curves (FORCs) of nano-engineered 3D Co-Fe structures. AIP Adv. 2020, 10, 015319. [CrossRef]

14. Nogués, J.; Schuller, I.K. Exchange Bias. J. Magn. Magn. Mater. 1999, 192, 203-232. [CrossRef]

15. Schneider, V.; Reinhold, A.; Kreibig, U.; Weirich, T.; Güntherodt, G.; Beschoten, B.; Tillmanns, A.; Krenn, H.; Rumpf, K.; Granitzer, P. Structural and magnetic properties of $\mathrm{Ni} / \mathrm{NiOxide}$ and $\mathrm{Co} / \mathrm{CoO}$ xide core/shell nanoparticles and their possible use for ferrofluids. Z. Phys. Chem. 2006, 220, 173-187. [CrossRef]

16. Tillmanns, A.; Blachowicz, T.; Fraune, M.; Güntherodt, G.; Schuller, I.K. Anomalous magnetization reversal mechanism in unbiased $\mathrm{Fe} / \mathrm{FeF}_{2}$ investigated by means of the magneto-optic Kerr effect. J. Magn. Magn. Mater. 2009, 321, 2932-2935. [CrossRef]

17. Nogués, J.; Sort, J.; Langlais, V.; Skumryev, V.; Surinach, S.; Munoz, J.S.; Baró, M.D. Exchange bias in nanostructures. Phys. Rep. 2005, 422, 65-117. [CrossRef]

18. Christou, G.; Gatteschi, D.; Hendrickson, D.N.; Sessoli, R. Single-molecule magnets. MRS Bulletin 2000, 25, 66-71. [CrossRef]

19. Bogani, L.; Wernsdorfer, W. Molecular spintronic using single-molecule magnets. Nat. Mater. 2008, 7, 179-186. [CrossRef] [PubMed]

20. Sessoli, R.; Powell, A.K. Strategies towards single molecule magnets based on lanthanide ions. Coord. Chem. Rev. 2009, 253, 2328-2341. [CrossRef]

21. Coulon, C.; Miyasaka, H.; Clérac, R. Single-chain magnets: Theoretical approach and experimental systems. Struct. Bond. 2006, 122, 163-206. [CrossRef]

22. Sun, H.-L.; Wang, Z.-M.; Gao, S. Strategies towards single-chain magnets. Coord. Chem. Rev. 2010, 254, 1081-1100. [CrossRef]

23. Böhme, M.; Plass, W. How to link theory and experiment for single-chain magnets beyond the Ising model: Magnetic properties modeled from ab initio calculations of molecular fragments. Chem. Sci. 2019, 10, 9189-9202. [CrossRef] 
24. Wu, B.-Y.; Yang, C.-I.; Nakano, M.; Lee, G.H. Ferromagnetic interaction and slow magnetic relaxation in a $\mathrm{Co}_{3}$ cluster-based three-dimensional framework. Dalton Trans. 2014, 43, 47-50. [CrossRef] [PubMed]

25. Yi, X.H.; Calvez, G.; Daiguebonne, C.; Guillou, O.; Bernot, K. Rational organization of lanthanide-based SMM dimers into three-dimensional networks. Inorg. Chem. 2015, 54, 5213-5219. [CrossRef]

26. Dutta, D.; Lefkidis, G.; Hübner, W. Role of the static correlations on the ultrafast spin dynamics of $3 d$ molecular nano-magnets. Phys. Scr. 2020, 95, 065805. [CrossRef]

27. Takahashi, M.; Turek, P.; Nakazawa, Y.; Tamura, M.; Nozawa, K.; Shiomi, D.; Ishikawa, M.; Kinoshita, M. Discovery of a quasi-1D organic ferromagnet, $p$-NPNN. Phys. Rev. Lett. 1992, 69, 1290. [CrossRef]

28. Mertes, K.M.; Suzuki, Y.; Sarachik, M.P.; Myasoedov, Y.; Shtrikman, H.; Zeldov, E.; Rumberger, E.M.; Hendrickson, D.N.; Christou, G. $\mathrm{Mn}_{12}$-acetate: A prototypical single molecule magnet. Solid State Commun. 2003, 127, 131-139. [CrossRef]

29. Murrie, M. Cobalt(II) single-molecule magnets. Chem. Soc. Rev. 2010, 39, 1986-1995. [CrossRef]

30. Cirillo, G.A.; Turvani, G.; Graziano, M. A quantum computation model for molecular nanomagnets. IEEE Trans. Nanotechnol. 2019, 18, 1027-1039. [CrossRef]

31. Rinehart, J.D.; Long, J.R. Exploiting single-ion anisotropy in the design of f-element single-molecule magnets. Chem. Sci. 2011, 2, 2078-2085. [CrossRef]

32. Liu, J.-L.; Chen, Y.-C.; Tong, M.-L. Symmetry strategies for high performance lanthanide-based single-molecule magnets. Chem. Soc. Rev. 2018, 47, 2431-2453. [CrossRef] [PubMed]

33. Xue, S.F.; Guo, Y.-N.; Ungur, L.; Tang, J.K.; Chibotaru, L.F. Tuning the magnetic interactions and relaxation dynamics of Dy 2 single-molecule magnets. Chem. Eur. J. 2015, 21, 14099-14106. [CrossRef]

34. Gupta, T.; Beg, M.F.; Rajaraman, G. Role of single-ion anisotropy and magnetic exchange interactions in suppressing zero-field tunneling in \{3d-4f\} single molecule magnets. Inorg. Chem. 2016, 55, 11201-11215. [CrossRef] [PubMed]

35. Zhang, L.; Zhang, Y.-Q.; Zhang, P.; Zhao, L.; Guo, M.; Tang, J.K. Single-molecule magnet behavior enhanced by synergic effect of single-ion anisotropy and magnetic interactions. Inorg. Chem. 2017, 56, 7882-7889. [CrossRef]

36. Guo, Y.-N.; Xu, G.-F.; Guo, Y.; Tang, J.K. Relaxation dynamics of dysprosium(III) single molecule magnets. Dalton Trans. 2011, 40, 9953-9963. [CrossRef]

37. Slater, J.C. Average energy of states of given multiplicities in atoms. Phys. Rev. 1968, 165, 655. [CrossRef]

38. Kahn, O.; Briat, B. Exchange interaction in polynuclear complexes. Part 1. Principles, model and application to the binuclear complexes of chromium. J. Chem. Soc. Faraday Trans. 2 Mol. Chem. Phys. 1976, 72, 268-281. [CrossRef]

39. Domanov, O.; Weschke, E.; Saito, T.; Peterlik, H.; Pichler, T.; Eisterer, M.; Shiozawa, H. Exchange coupling in a frustrated trimetric molecular magnet reversed by a 1D nano-confinement. Nanoscale 2019, 11, 10615-10621. [CrossRef]

40. Anderson, P.W.; Hasegawa, H. Considerations on double exchange. Phys. Rev. 1955, 100, 675. [CrossRef]

41. Borras-Almenar, J.J.; Clemente-Juan, J.M.; Coronado, E.; Mirovitskii, V.Y.; Palii, A.V.; Tsukerblat, B.S. Double exchange in orbitally degenerate mixed valence clusters: Magnetic anisotropy, vibronic effects. In Vibronic Interactions: Jahn-Teller Effect in Crystals and Molecules; Kaplan, M.D., Zimmerman, G.O., Eds.; Springer: Dordrecht, The Netherlands, 2001; Volume 39, pp. 111-122.

42. Aubin, S.M.J.; Wemple, M.W.; Adams, D.M.; Tsai, H.-L.; Christou, G.; Hendrickson, D.N. Distorted $\mathrm{Mn}^{\mathrm{IV}} \mathrm{Mn}^{\mathrm{III}}{ }_{3} \mathrm{Cubane} \mathrm{complexes}$ as single-molecule magnets. J. Am. Chem. Soc. 1996, 118, 7746-7754. [CrossRef]

43. Sessoli, R.; Gatteschi, D.; Caneschi, A.; Novak, M.A. Magnetic bistability in a metal-ion cluster. Nature 1993, 365, 141-143. [CrossRef]

44. Aubin, S.M.J.; Sun, Z.M.; Pardi, L.; Krzystek, J.; Folting, K.; Brunel, L.-C.; Rheingold, A.L.; Christou, G.; Hendrickson, D.N. Reduced anionic $\mathrm{Mn}_{12}$ molecules with half-integer ground states as single-molecule magnets. Inorg. Chem. 1999, 38, 5329-5340. [CrossRef]

45. Gatteschi, D.; Sessoli, R.; Cornia, A. Single-molecule magnets based on iron(III) oxo clusters. Chem. Commun. 2000, 2000, 725-732. [CrossRef]

46. Friedman, J.R.; Sarachik, M.P.; Tejada, J.; Maciejewski, J.; Ziolo, R. Steps in the hysteresis loops of a high-spin molecule. J. Appl. Phys. 1996, 79, 6031. [CrossRef]

47. Friedman, J.R.; Sarachik, M.P.; Tejada, J.; Ziolo, R. Macroscopic measurement of resonant magnetization tunneling in high-spin molecules. Phys. Rev. Lett. 1996, 76, 3830. [CrossRef] [PubMed]

48. Wernsdorfer, W.; Sessoli, R.; Caneschi, A.; Gatteschi, D.; Cornia, A.; Mailly, D. Landau-Zener method to study quantum phase interference of $\mathrm{Fe}_{8}$ molecular nanomagnets. J. Appl. Phys. 2000, 87, 5481. [CrossRef]

49. Sangregoria, C.; Ohm, T.; Paulsen, C.; Sessoli, R.; Gatteschi, D. Quantum Tunneling of the magnetization in an iron cluster nanomagnet. Phys. Rev. Lett. 1997, 78, 4645. [CrossRef]

50. Aubin, S.M.J.; Dilley, N.R.; Pardi, L.; Krzystek, J.; Wemple, M.W.; Brunel, L.C.; Maple, M.B.; Christou, G.; Hendrickson, D.N. Resonant magnetization tunneling in the trigonal pyramidal $\mathrm{Mn}^{\mathrm{IV}} \mathrm{Mn}_{3}^{\mathrm{III}}$ complex $\left[\mathrm{Mn}_{4} \mathrm{O}_{3} \mathrm{Cl}_{(}\left(\mathrm{O}_{2} \mathrm{CCH}_{3}\right)_{3}(\mathrm{dbm})_{3}\right.$. J. Am. Chem. Soc. 1998, 120, 4991-5004. [CrossRef]

51. Shao, D.; Wang, X.Y. Development of single-molecule magnets. Chin. J. Chem. 2020, 38, 1005-1018. [CrossRef]

52. Li, M.; Wu, H.P.; Xia, Z.Q.; Ungur, L.; Liu, D.; Chibotaru, L.F.; Ke, H.S.; Chen, S.P.; Gao, S.L. An inconspicuous six-coordinate neutral Dy ${ }^{\mathrm{III}}$ single-ion magnet with remarkable magnetic anisotropy and stability. Inorg. Chem. 2020, 59, 7158-7166. [CrossRef] 
53. Chiesa, A.; Cugini, F.; Hussain, R.; Macaluso, E.; Allodi, G.; Garlatti, E.; Giansiracusa, M.; Goodwin, C.A.P.; Ortu, F.; Reta, D.; et al. Understanding magnetic relaxation in single-ion magnets with high blocking temperature. Phys. Rev. B 2020, 101, 174402. [CrossRef]

54. Jin, P.B.; Zhai, Y.Q.; Yu, K.X.; Winpenny, R.E.P.; Zheng, Y.Z. Dysprosiacarboranes as organometallic single-molecule magnets. Angew. Chem. Int. Ed. 2020, 59, 9350-9354. [CrossRef]

55. Spree, L.; Schlesier, C.; Kostanyan, A.; Westerström, R.; Greber, T.; Büchner, B.; Avdoshenko, S.M.; Popov, A.A. Single-Molecule Magnets $\mathrm{DyM}_{2} \mathrm{~N} @ \mathrm{C}_{80}$ and $\mathrm{Dy}_{2} \mathrm{MN}_{\mathrm{C}} \mathrm{C}_{80}(\mathrm{M}=\mathrm{Sc}, \mathrm{Lu})$ : The Impact of Diamagnetic Metals on Dy ${ }^{3+}$ Magnetic Anisotropy, Dy...Dy Coupling, and Mixing of Molecular and Lattice Vibrations. Chem. Eur. J. 2020, 26, 2436-2449. [CrossRef] [PubMed]

56. Nie, M.Z.; Xiong, J.; Zhao, C.; Meng, H.B.; Zhang, K.; Han, Y.B.; Li, J.; Wang, B.W.; Feng, L.; Wang, C.R.; et al. Luminescent single-molecule magnet of metallofullerene DyErScN@I $I_{h}-C_{80}$. Nano Res. 2019, 12, 1727-1731. [CrossRef]

57. Velkos, G.; Krylov, D.S.; Kirkpatrick, K.; Spree, L.; Dubrovin, V.; Büchner, B.; Avdoshenko, S.M.; Bezmelnitsyn, V.; Davis, S.; Faust, P.; et al. High Blocking Temperature of Magnetization and Giant Coercivity in the Azafullerene Tb-2@C79N with a Single-Electron Terbium-Terbium Bond. Angew. Chem. Int. Ed. 2019, 58, 5891-5896. [CrossRef] [PubMed]

58. Díaz-Orgeta, I.F.; Herrera, J.M.; Dey, S.; Nojiri, H.; Rajaraman, G.; Colacio, E. The effect of the electronic structure and flexibility of the counteranions on magnetization relaxation in $\left[\mathrm{Dy}(\mathrm{L})_{2}\left(\mathrm{H}_{2} \mathrm{O}\right)_{5}\right]^{3+}(\mathrm{L}=$ phosphine oxide derivative $)$ pentagonal bipyramidal SIMs. Inorg. Chem. Front. 2020, 7, 689-699. [CrossRef]

59. Gould, C.A.; McClain, K.R.; Yu, J.M.; Groshens, T.J.; Furche, F.; Harvey, B.G.; Long, J.R. Synthesis and Magnetism of Neutral, Linear Metallocene Complexes of Terbium(II) and Dysprosium(II). J. Am. Chem. Soc. 2019, 141, 12967-12973. [CrossRef] [PubMed]

60. Guo, F.S.; Day, B.M.; Chen, Y.C.; Tong, M.L.; Mansikkamaki, A.; Layfield, R.A. Magnetic hysteresis up to 80 Kelvin in a dysprosium metallocene single-molecule magnet. Science 2018, 362, 1400-1403. [CrossRef]

61. McClain, K.R.; Gould, C.A.; Chakarawet, K.; Teat, S.J.; Groshens, T.J.; Long, J.R.; Harvey, B.G. High-temperature magnetic blocking and magneto-structural correlations in a series of dysprosium(III) metallocenium single-molecule magnets. Chem. Sci. 2018, 9, 8492-8503. [CrossRef]

62. Guo, F.-S.; Day, B.M.; Chen, Y.-C.; Tong, M.-L.; Mansikkamäki, A.; Layfield, R.A. A Dysprosium metallocene single molecule magnet functioning at the axial limit. Angew. Chem. Int. Ed. 2017, 56, 11445. [CrossRef]

63. Goodwin, C.A.P.; Ortu, F.; Reta, D.; Chilton, N.F.; Mills, D.P. Molecular magnetic hysteresis at 60 Kelvin in dysprosocenium. Nature 2017, 548, 439-442. [CrossRef]

64. Feltham, H.L.C.; Clérac, R.; Ungur, L.; Chibotaru, L.F.; Powell, A.K.; Brooker, S. By design: A macrocyclic 3d-4f single-molecule magnet with quantifiable zero-field slow relaxation of magnetization. Inorg. Chem. 2013, 52, 3236-3240. [CrossRef]

65. Osa, S.; Kido, T.; Matsumoto, N.; Re, N.; Pochaba, A.; Mrozinski, J. A tetranuclear 3d-4f single molecule magnet: $\left[\mathrm{Cu}^{\mathrm{II} L T b}{ }^{\mathrm{III}}(\mathrm{hfac})_{2}\right]_{2}$. J. Am. Chem. Soc. 2004, 126, 420-421. [CrossRef]

66. Chilton, N.F.; Langley, S.K.; Moubaraki, B.; Murray, K.S. Synthesis, structural and magnetic studies of an isostructural family of mixed 3d/4f tetranuclear "star" clusters. Chem. Commun. 2010, 46, 7787-7789. [CrossRef]

67. Dey, A.; Acharya, J.; Chandrasekhar, V. Heterometallic 3d-4f complexes as single-molecule magnets. Chem. Asian J. 2019, 14, 4433-4453. [CrossRef]

68. Chakraborty, A.; Goura, J.; Kalita, P.; Swain, A.; Rajaraman, G.; Chandrasekhar, V. Heterometallic 3d-4f single molecule magnets containing diamagnetic metal ions. Dalton Trans. 2018, 47, 8841-8864. [CrossRef]

69. Zheng, F.-W.; Chen, H.-T.; Li, D.-J.; Han, F.-J.; Yang, L. Two types of $\{$ FeDy $\}$ heterometallic complexes containing Fe 4 structure: Carboxylate derivatives effect on the structures and magnetic properties. J. Clust. Sci. 2020, 32, 461-467. [CrossRef]

70. Hou, Y.L.; Yang, T.T.; Zhao, W.X.; Fan, C.J.; Yan, L.L.; Guan, X.F.; Ji, J.; Wang, W.M. Modulating SMM behaviors in phenoxo-O bridged Dy, compounds via different $\beta$-diketonate. Inorg. Chim. Act. 2020, 507, 119595.

71. Das, V.; Kaushik, R.; Hussain, F. Heterometallic 3d-4f polyoxometalates: An emerging field with structural diversity to multiple applications. Coord. Chem. Rev. 2020, 413, 213271. [CrossRef]

72. Wang, Y.Y.; Du, C.Y.; Zhao, L.H.; Zhang, X.; Wang, D.H.; Sha, J.Q.; Zhang, H.F. Two hexanuclear $\left[\mathrm{Co}_{2}{ }^{\mathrm{III}}-\mathrm{Ln}_{4}{ }^{\mathrm{III}}\right] \mathrm{clusters} \mathrm{including}^{\mathrm{I}}$ a $\left[\mathrm{CO}_{2}{ }^{\mathrm{III}}-\mathrm{Dy}_{4}{ }^{\mathrm{III}}\right.$ ] single molecule magnet. Inorg. Chem. Commun. 2020, 116, 107913. [CrossRef]

73. Xue, S.F.; Zhao, L.; Guo, Y.-N.; Deng, R.P.; Guo, Y.; Tang, J.K. A series of tetranuclear lanthanide complexes comprising two edge-sharing triangular units with field-induced slow magnetic relaxation for Dy 4 species. Dalton Trans. 2011, 40, 8347-8352. [CrossRef]

74. Feuersenger, J.; Prodius, D.; Mereacre, V.; Clérac, R.; Anson, C.E.; Powell, A.K. Synthesis, structure and magnetic properties of hexanuclear Co ${ }^{\text {III }}-$ Ln $^{\text {III }}$ clusters. Polyhedron 2013, 66, 257-263. [CrossRef]

75. Wang, Y.Y.; Ma, Y.Q.; Liu, R.; Yang, L.L.; Tian, G.G.; Shen, N. Tetranuclear complexes with $\left\{M_{4} \mathrm{O}_{4}\right\}\left(M=\mathrm{Co}^{\mathrm{II}}, \mathrm{Ni}^{\mathrm{II}}\right)$ Cubane-Like Core: Synthesis, Crystal Structure, and Magnetic Properties. Z. Anorg. Allg. Chem. 2016, 642, 546-550. [CrossRef]

76. Wang, R.R.; Wang, H.L.; Wang, J.; Bai, F.F.; Ma, Y.; Li, L.C.; Wang, Q.L.; Zhao, B.; Cheng, P. The different magnetic relaxation behaviors in $\left[\mathrm{Fe}(\mathrm{CN})_{6}\right]^{3-}$ or $\left[\mathrm{Co}(\mathrm{CN})_{6}\right]^{3-}$ bridged 3d-4f heterometallic compounds. CrystEngComm 2020, 22, 2998-3004. [CrossRef]

77. Liu, Y.; Chen, Y.-C.; Liu, J.; Chen, W.-B.; Huang, G.-Z.; Wu, S.-G.; Wang, J.; Liu, J.-L.; Tong, M.-L. Cyanometallate-bridged didysprosium single-molecule magnets constructed with single-ion magnet building block. Inorg. Chem. 2020, 59, 687-694. [CrossRef] 
78. Yin, Y.; Wang, J.H.; Zychowicz, M.; Zakrzewski, J.J.; Nakabayashi, K.; Sieklucka, B.; Chorazy, S.; Ohkoshi, S.-I. Dehydrationhydration switching of single-molecule magnet behavior and visible photoluminescence in a cyanide-bridged Dy ${ }^{\mathrm{III}} \mathrm{Co}{ }^{\mathrm{III}}$ framework. J. Am. Chem. Soc. 2019, 141, 18211-18220.

79. Zakrzewski, J.J.; Liberka, M.; Zychowicz, M.; Chorazy, S. Diverse physical functionalities of rare-earth hexacyanidometallate frameworks and their molecular analogues. Inorg. Chem. Front. 2021, 8, 452-483. [CrossRef]

80. Babeshkin, K.A.; Gavrikov, A.V.; Petrosyants, S.P.; Ilyukhin, A.B.; Belova, E.V.; Efimov, N.N. Unexpected supremacy of nondysprosium single-ion magnets within a series of isomorphic lanthanide cyanocobaltate(III) complexes. Eur. J. Inorg. Chem. 2020, 2020, 4380-4390. [CrossRef]

81. Lun, H.-J.; Kong, X.-J.; Long, L.-S.; Zheng, L.-S. Trigonal bipyramidal $\mathrm{Co}_{2}^{\mathrm{III}}{ }_{2} \mathrm{y}_{3}$ cluster exhibiting single-molecule magnet behavior. Dalton Trans. 2020, 49, 2421-2425. [CrossRef]

82. Zhang, J.-W.; Li, W.-H.; Wang, C.-R.; Liu, B.-Q.; Dong, Y.-P. A series of linear $\mathrm{Co}_{2}{ }_{2} \mathrm{Ln}^{\mathrm{III}}{ }_{2}$ clusters derived from 3,4-dichlorobenzoate and 2,2'-bipyridine: Syntheses, structures, and properties. Inorg. Chim. Acta 2020, 502, 119343. [CrossRef]

83. Xi, L.; Sun, J.; Wang, K.; Lu, J.; Jing, P.; Li, L.C. Slow magnetic relaxation in Co ${ }^{\mathrm{II}}-\mathrm{Ln}^{\mathrm{III}}$ heterodinuclear complexes achieved through a functionalized nitronyl nitroxide biradical. Dalton Trans. 2020, 49, 1089-1096. [CrossRef]

84. Yu, Y.Z.; Pan, X.X.; Cui, C.H.; Luo, X.M.; Li, N.F.; Mei, H.; Xu, Y. A Series Three-Dimensional $\mathrm{Ln}_{4} \mathrm{Cr}_{4}(\mathrm{Ln}=\mathrm{Gd}, \mathrm{Tb}, \mathrm{Er})$ Heterometallic Cluster-Based Coordination Polymers Containing Interesting Nanotubes Exhibiting High Magnetic Entropy. Inorg. Chem. 2020, 59, 5593-5599. [CrossRef]

85. Fan, X.-T.; Yang, H.; Li, D.-C.; Tian, H.-Q.; Cao, F.; Dou, J.-M. Three new heterometallic Zn ${ }^{\text {II }-L n ~}{ }^{\text {III }}$ complexes with a windmill-like framework and field-induced SMM behavior. New J. Chem. 2020, 44, 2555-2560. [CrossRef]

86. Maity, S.; Mondal, A.; Konar, S.; Ghosh, A. The role of 3d-4f exchange interaction in SMM behaviour and magnetic refrigeration of carbonato bridged $\mathrm{Cu}{ }_{2}{ }_{2} \mathrm{Ln}{ }_{2}$ III $\left(\mathrm{Ln}=\mathrm{Dy}, \mathrm{Tb}\right.$ and $\mathrm{Gd}$ ) complexes of an unsymmetrical $\mathrm{N}_{2} \mathrm{O}_{4}$ donor ligand. Dalton Trans. 2019, 48, 15170-15183. [CrossRef]

87. Darii, M.; Kravtsov, V.C.; Krämer, K.; Hauser, J.; Decurtins, S.; Liu, S.-X.; Affronte, M.; Baca, S.G. Aggregation of a Giant Bean-like $\left\{\mathrm{Mn}_{26} \mathrm{Dy}_{6}\right\}$ Heterometallic Oxo-Hydroxo-Carboxylate Nanosized Cluster from a Hexanuclear $\left\{\mathrm{Mn}_{6}\right\}$ Precursor. Cryst. Growth Des. 2020, 20, 33-38. [CrossRef]

88. Gao, F.; Feng, X.W.; Yang, L.; Chen, X.Y. New sandwich-type lanthanide complexes based on closed-macrocyclic Schiff base and phthalocyanine molecules. Dalton Trans. 2016, 45, 7476-7482. [CrossRef]

89. Li, Z.G.; Gao, F.; Xiao, Z.G.; Wu, X.Z.; Zuo, J.L.; Song, Y.L. Nonlinear optical properties and excited state dynamics of sandwichtype mixed (phthalocyaninato)(Schiff-base) triple-decker complexes: Effect of rare earth atom. Opt. Laser Technol. 2018, $103,42-47$. [CrossRef]

90. Wang, H.L.; Cao, W.; Liu, T.; Duan, C.Y.; Jiang, J.H. Synthesis, Structure, and Single-Molecule Magnetic Properties of Rare-Earth Sandwich Complexes with Mixed Phthalocyanine and Schiff Base Ligands. Chem. Eur. J. 2013, 19, 2266-2270. [CrossRef]

91. Suzuki, A.; Oku, T. Effects of central metal on electronic structure, magnetic properties, infrared and Raman spectra of doubledecker phthalocyanine. Appl. Surf. Sci. 2016, 380, 127-134. [CrossRef]

92. Sato, T.; Matsuzawa, S.; Kato, K.; Breedlove, B.K.; Yamashita, M. Relationship between the Coordination Geometry and Spin Dynamics of Dysprosium(III) Heteroleptic Triple-Decker Complexes. Magnetochemistry 2019, 5, 65. [CrossRef]

93. Patrascu, A.A.; Briganti, M.; Soriano, S.; Clancea, S.; Cassaro, R.A.A.; Totti, F.; Vaz, M.G.F.; Andruh, M. SMM Behavior Tuned by an Exchange Coupling LEGO Approach for Chimeric Compounds: First 2p-3d-4f Heterotrispin Complexes with Different Metal Ions Bridged by One Aminoxyl Group. Inorg. Chem. 2019, 58, 13090-13101. [CrossRef]

94. Patrascu, A.A.; Calancea, S.; Briganti, M.; Soriano, S.; Madalan, A.M.; Cassaro, R.A.A.; Caneschi, A.; Totti, F.; Vaz, M.G.F.; Andruh, M. A chimeric design of heterospin $2 p-3 d, 2 p-4 f$, and $2 p-3 d-4 f$ complexes using a novel family of paramagnetic dissymmetric compartmental ligands. Chem. Commun. 2017, 53, 6504-6507. [CrossRef]

95. Feng, M.; Tong, M.L. Single ion magnets from 3d to 5f: Developments and strategies. Chem. A Eur. J. 2018, 24, 7574-7594. [CrossRef] [PubMed]

96. Lunghi, A.; Totti, F.; Sessoli, R.; Sanvito, S. The role of anharmonic phonons in under-barrier spin relaxation of single molecule magnets. Nat. Commun. 2017, 8, 14620. [CrossRef]

97. Lunghi, A.; Totti, F.; Sanvito, S.; Sessoli, R. Intra-molecular origin of the spin-phonon coupling in slow-relaxing molecular magnets. Chem. Sci. 2017, 8, 6051-6059. [CrossRef] [PubMed]

98. Lunghi, A.; Sanvito, S. How do phonons relax molecular spins? Sci. Adv. 2019, 5, eaax7163. [CrossRef]

99. Vonci, M.; Giansiracusa, M.J.; van den Heuvel, W.; Gable, R.W.; Moubaraki, B.; Murray, K.S.; Yu, D.; Mole, R.A.; Soncini, A.; Boskovic, C. Magnetic Excitations in Polyoxotungstate-Supported Lanthanoid Single-Molecule Magnets: An Inelastic Neutron Scattering and ab Initio Study. Inorg. Chem. 2017, 56, 378-394. [CrossRef]

100. Gransbury, G.K.; Boulon, M.-E.; Mole, R.A.; Gable, R.W.; Moubaraki, B.; Murray, K.S.; Sorace, L.; Soncini, A.; Boskovic, C. Single-ion anisotropy and exchange coupling in cobalt(II)-radical complexes: Insights from magnetic and ab initio studies. Chem. Sci. 2019, 10, 8855-8871. [CrossRef]

101. Sorensen, M.A.; Hansen, U.B.; Perfetti, M.; Pedersen, K.S.; Bartolomé, E.; Simeoni, G.G.; Mutka, H.; Rols, S.; Jeong, M.; Zivkovic, I.; et al. Chemical tunnel-splitting-engineering in a dysprosium-based molecular nanomagnet. Nat. Commun. 2018, 9, 1292. [CrossRef] [PubMed] 
102. Perfetti, M.; Sorensen, M.A.; Hansen, U.B.; Bamberger, H.; Lenz, S.; Hallmen, P.P.; Fennell, T.; Simeoni, G.G.; Arauzo, A.; Bartolomé, J.; et al. Magnetic anisotropy switch: Easy axis to easy plane conversion and vice versa. Adv. Funct. Mater. 2018, $28,1801846$. [CrossRef]

103. Bonde, N.A.; Petersen, J.B.; Sorensen, M.A.; Nielsen, U.G.; Fak, B.; Rols, S.; Ollivier, J.; Weihe, H.; Bendix, J.; Perfetti, M. Importance of Axial Symmetry in Elucidating Lanthanide-Transition Metal Interactions. Inorg. Chem. 2020, 59, 235-243. [CrossRef]

104. Pointillart, F.; Gonzales, J.F.; Montigaud, V.; Tesi, L.; Cherkasov, V.; Le Guennic, B.; Cador, O.; Ouahab, L.; Sessoli, R.; Kuropatov, V. Redox- and solvato-magnetic switching in a tetrathiafulvalene-based triad single-molecule magnet. Inorg. Chem. Front. 2020, 7 , 2322-2334. [CrossRef]

105. Cador, O.; Le Guennic, B.; Ouahab, L.; Pointillart, F. Decorated Tetrathiafulvalene-Based Ligands: Powerful Chemical Tools for the Design of Single-Molecule Magnets. Eur. J. Inorg. Chem. 2020, 2020, 148-164. [CrossRef]

106. Yao, X.-N.; Du, J.-Z.; Zhand, Y.-Q.; Leng, X.-B.; Yang, M.-W.; Jiang, S.-D.; Wang, Z.-X.; Qouyang, Z.-W.; Deng, L.; Wang, B.-W.; et al. Two-coordinate Co(II) imido complexes as outstanding single-molecule magnets. J. Am. Chem. Soc. 2017, 139, 373-380. [CrossRef]

107. Bunting, P.C.; Atanasov, M.; Damgaard-Moller, E.; Perfetti, M.; Crassee, I.; Orlita, M.; Overgaard, J.; van Slageren, J.; Neese, F.; Long, J.R. A linear cobalt(II) complex with maximal orbital angular momentum from a non-Aufbau ground state. Science 2018, 362, eaat7319. [CrossRef]

108. Caneschi, A.; Gatteschi, D.; Lalioti, N.; Sangregorio, C.; Sessoli, R.; Venturi, G.; Vindigni, A.; Rettori, A.; Pini, M.G.; Novak, M.A. Cobalt(II)-Nitronyl Nitroxide Chains as Molecular Magnetic Nanowires. Angew. Chem. Int. Ed. 2001, 40, 1760-1763. [CrossRef]

109. Clérac, R.; Miyasaka, H.; Yamashita, M.; Coulon, C. Evidence for Single-Chain Magnet Behavior in a Mn ${ }^{\mathrm{III}}-\mathrm{Ni}^{\mathrm{II}} \mathrm{Chain} \mathrm{Designed}$ with High Spin Magnetic Units: A Route to High Temperature Metastable Magnets. J. Am. Chem. Soc. 2002, 124, 12837-12844. [CrossRef] [PubMed]

110. Lescouezec, R.; Vaissermann, J.; Ruiz-Pérez, C.; Lloret, F.; Carrasco, R.; Julve, M.; Verdaguer, M.; Dromzee, Y.; Geteschi, D.; Wernsdorfer, W. Cyanide-Bridged Iron(III)-Cobalt(II) Double Zigzag Ferromagnetic Chains: Two New Molecular Magnetic Nanowires. Angew. Chem. Int. Ed. 2003, 42, 1483-1486. [CrossRef] [PubMed]

111. Sun, Z.M.; Prosvirin, A.V.; Zhao, H.H.; Mao, J.G.; Dunbar, K.R. New type of single chain magnet based on spin canting in an antiferromagnetically coupled Co(II) chain. J. Appl. Phys. 2005, 97, 10B305. [CrossRef]

112. Tanaka, H.; Kajiwara, T.; Kaneko, Y.; Takaishi, S.; Yamashita, M. Synthesis, structure, and magnetic property of a new Fe(II)-Fe(III) alternating single-chain magnet constructed with a methyl-substituted bpca ${ }^{-}$ligand. Polyhedron 2007, 26, 2105-2109. [CrossRef]

113. Bogani, L.; Vindigni, A.; Sessoli, R.; Gatteschi, D. Single chain magnets: Where to from here? J. Mater. Chem. 2008, 18, 4750-4758. [CrossRef]

114. Zhang, W.-X.; Ishikawa, R.; Breedlove, B.; Yamashita, M. Single-chain magnets: Beyond the Glauber model. RSC Adv. 2013, 3, 3772-3798. [CrossRef]

115. Nadeem, M.A.; Ng, M.C.C.; van Leusen, J.; Kogerler, P.; Stride, J.A. Magnetic phase transitions in a $\mathrm{Ni}_{4} \mathrm{O}_{4}$-cubane-based metal-organic framework. Chem. A Eur. J. 2020, 26, 7589-7594. [CrossRef]

116. Liu, X.Q.; Feng, X.W.; Meihaus, K.R.; Meng, X.X.; Zhang, Y.; Li, L.; Liu, J.L.; Pedersen, K.S.; Keller, L.; Shi, W.; et al. Coercive fields above $6 \mathrm{~T}$ in two cobalt(II)-radical chain compounds. Angew. Chem. Int. Ed. 2020, 59, 10610-10618. [CrossRef]

117. Yang, J.; Deng, Y.F.; Zhang, Y.Z. Two azido-bridged homospin Fe(II)/Co(II) coordination polymers featuring single-chain magnet behavior. Dalton Trans. 2020, 49, 4805-4810. [CrossRef]

118. Shi, L.; Shao, D.; Wei, X.-Q.; Dunbar, K.R.; Wang, X.-Y. Enhanced single-chain magnet behavior via anisotropic exchange in a cyano-bridged Mo ${ }^{\mathrm{III}}-\mathrm{Mn}^{\mathrm{II}}$ chain. Angew. Chem. Int. Ed. 2020, 59, 10379-10384. [CrossRef]

119. Jiang, W.-J.; Lu, H.-H.; Meng, Y.-S.; Jiao, C.-Q.; Liu, T. Dehydration-actuated single-chain magnet through charge transfer in a cyanide-bridged $\mathrm{Fe}_{2} \mathrm{Co}$ chain. Inorg. Chem. Comm. 2020, 112, 107715. [CrossRef]

120. Korzeniak, T.; Nowicka, B.; Sieklucka, B. Hybrid organic-inorganic cyanide-bridged networks. In Organometallic Magnets; Chandrasekhar, V., Pointillart, F., Eds.; Topics in Organometallic Chemistry; Springer: Cham, Switzerland, 2019; Volume 64, pp. 1-34.

121. Reczynski, M.; Nowicka, B.; Näther, C.; Koziel, M.; Nakabayashi, K.; Ohkoshi, S.-I.; Sieklucka, B. Dehydration-Triggered Charge Transfer and High Proton Conductivity in $\left(\mathrm{H}_{3} \mathrm{O}\right)\left[\mathrm{Ni}^{\mathrm{III}}(\right.$ cyclam $\left.)\right]\left[\mathrm{M}^{\mathrm{II}}(\mathrm{CN})_{6}\right](\mathrm{M}=\mathrm{Ru}, \mathrm{Os})$ Cyanide-Bridged Chains. Inorg. Chem. 2018, 57, 13415-13422. [CrossRef]

122. Sieklucka, B.; Pinkowicz, D. (Eds.) Molecular Magnetic Materials; Wiley-VCH Verlag GmbH \& Co. KGaA: Weinheim, Germany, 2017.

123. Alexandru, M.-G.; Visinescu, D.; Shova, S.; Lloret, F.; Julve, M. Cyanido-Bridged $\left\{\mathrm{Ln}^{\mathrm{III}} \mathrm{W}^{\mathrm{V}}\right\}$ Heterobinuclear Complexes: Synthesis and Magneto-Structural Study. Inorg. Chem. 2017, 56, 12594-12605. [CrossRef]

124. Wei, R.-M.; Cao, F.; Li, J.; Yang, L.; Han, Y.; Zhang, X.-L.; Zhang, Z.C.; Wang, X.-Y.; Song, Y. Single-Chain Magnets Based on Octacyanotungstate with the Highest Energy Barriers for Cyanide Compounds. Sci. Rep. 2016, 6, 24372. [CrossRef] [PubMed]

125. Zhang, Y.-Z.; Dolinar, B.S.; Liu, S.H.; Brown, A.J.; Zhang, X.; Wang, Z.-X.; Dunbar, K.R. Enforcing Ising-like magnetic anisotropy via trigonal distortion in the design of a W(V)-Co(II) cyanide single-chain magnet. Chem. Sci. 2018, 9, 119-124. [CrossRef] [PubMed]

126. Yang, M.; Liang, X.H.; Zhang, Y.D.; Ouyang, Z.J.; Dong, W. A family of 3d-4f Cu-Ln ladder-like complexes: Synthesis, structures and magnetic properties. Polyhedron 2020, 180, 114435. [CrossRef]

127. Rubín, J.; Badía-Romano, L.; Luis, F.; Mereacre, V.; Prodius, D.; Arauzo, A.; Bartolomé, F.; Bartolomé, J. Magnetic chains of Fe 3 clusters in the $\left\{\mathrm{Fe}_{3} \mathrm{YO}_{2}\right\}$ butterfly molecular compound. Dalton Trans. 2020, 49, 2979-2988. [CrossRef] 
128. Yang, M.; Liang, X.H.; Zhang, Y.; Ouyang, Z.J.; Dong, W. A nitronyl nitroxide and its two 1D chain Cu-Tb complexes: Synthesis, structures, and magnetic properties. RSC Adv. 2020, 10, 8490-8496. [CrossRef]

129. Houard, F.; Evrard, Q.; Calvez, G.; Suffren, Y.; Daiguebonne, C.; Guillou, O.; Gendron, F.; Le Guennic, B.; Guizouarn, T.; Dorcet, V.; et al. Chiral supramolecular nanotubes of single-chain magnets. Angew. Chem. Int. Ed. 2020, 59, 780-784. [CrossRef]

130. Zhang, S.-L.; Li, S.-S.; Zeng, S.-Y.; Shi, Y.; Wang, D.-Q.; Chen, L. Slow magnetic relaxation in O-Se-O bridged manganese(III) Schiff base complexes. New J. Chem. 2020, 44, 2408-2413. [CrossRef]

131. Zhao, F.; Dong, Z.-P.; Liu, Z.-L.; Wang, Y.-Q. An unusual homospin Co $\mathrm{Co}^{\mathrm{II}}$ ferrimagnetic single-chain magnet with large hysteresis. CrystEngComm 2019, 21, 6958-6983. [CrossRef]

132. Zang, J.; Zhao, Q.-N.; Yang, F.; Yin, L.; Li, M.-M.; Wang, Z.X.; Ouyang, Z.W.; Xia, Z.-C.; Hu, T.-P. A cobalt(II) chain based on pymca generated in situ from the hydrolysis of 2-cyanopyrimidine: Spin canting and magnetic relaxation. RSC Adv. 2019, 9, 31115-31121. [CrossRef]

133. Wang, M.M.; Gou, X.S.; Shi, W.; Cheng, P. Single-chain magnets assembled in cobalt(ii) metal-organic frameworks. Chem. Commun. 2019, 55, 11000-11012. [CrossRef]

134. Takahashi, S.; Tupitsyn, I.S.; van Tol, J.; Beedle, C.C.; Hendrickson, D.N.; Stamp, P.C.E. Decoherence in crystals of quantum molecular magnets. Nature 2011, 476, 76-79. [CrossRef] [PubMed]

135. Landau, L. Zur Theorie der Energieübertragung. Phys. Z. Sov. 1932, 2, 46-51.

136. Zener, C. Non-adiabatic crossing of energy levels. Proc. R. Soc. Lond. A 1932, 137, 696-702.

137. Troiani, F.; Godfrin, C.; Thiele, S.; Balestro, F.; Wernsdorfer, W.; Klyatskaya, S.; Ruben, M.; Affronte, M. Landau-Zener transition in a continously measured single-molecule spin transistor. Phys. Rev. Lett. 2017, 118, 257701. [CrossRef]

138. Mirzoyan, R.; Hadt, R.G. The dynamic ligand field of a molecular qubit: Decoherence through spin-phonon coupling. Phys. Chem. Chem. Phys. 2020, 22, 11249-11265. [CrossRef] [PubMed]

139. Postnikov, A.V.; Kortus, J.; Pederson, M.R. Density functional studies of molecular magnets. Phys. Status Solidi B 2006, 243, 2533-2572. [CrossRef]

140. Taran, G.; Bonet, E.; Wernsdorfer, W. Decoherence measurements in crystals of molecular magnets. Phys. Rev. B 2019, 99, 180408(R). [CrossRef]

141. Lunghi, A.; Sanvito, S. Electronic spin-spin decoherence contribution in molecular qubits by quantum unitary spin dynamics. J. Magn. Magn. Mater. 2019, 487, 165325. [CrossRef]

142. Hu, C.; Chen, J.; Zhang, X.G. Modeling Hyperfine Coupling in Molecular Magnets. Bull. Am. Phys. Soc. 2020, 65, D12. 00007. Available online: https:/ / meetings.aps.org/Meeting/MAR20/Session/D12.7 (accessed on 3 July 2021).

143. Stamp, P.C.E. Environment decoherence versus intrinsic decoherence. Philos. Trans. R. Soc. A 2012, 370, 4429-4453. [CrossRef]

144. Liu, J.; Wu, B.; Fu, L.B.; Diener, R.B.; Niu, Q. Quantum step heights in hysteresis loops of molecular magnets. Phys. Rev. B 2002, 65, 224401. [CrossRef]

145. Bhandary, S.; Ghosh, S.; Herper, H.; Wende, H.; Eriksson, O.; Sanyal, B. Graphene as a reversible spin manipulator of molecular magnets. Phys. Rev. Lett. 2011, 107, 257202. [CrossRef]

146. Baker, M.L.; Timco, G.A.; Piligkos, S.; Mathieson, J.S.; Mutka, H.; Tuna, F.; Kozlowski, P.; Antkowiak, M.; Guidi, T.; Rath, H. A classification of spin frustration in molecular magnets from a physical study of large odd-numbered-metal, odd electron rings. Proc. Natl. Acad. Sci. USA 2012, 109, 19113-19118. [CrossRef]

147. Abufager, P.N.; Robles, R.; Lorente, N. FeCoCp 3 molecular magnets as spin filters. J. Phys. Chem. C 2015, 119, 12119-12129. [CrossRef]

148. Vieru, V.; Ungur, L.; Cemortan, V.; Sukhanov, A.; Baniodeh, A.; Anson, C.E.; Powell, A.K.; Voronkova, V.; Chibotaru, L.F. Magnetization blocking in $\mathrm{Fe}_{2}{ }^{\mathrm{III}} \mathrm{Dy}{ }^{2 \mathrm{III}}$ molecular magnets: Ab initio calculations and EPR spectroscopy. Chem. Eur. J. 2018, 24, 16652-16661. [CrossRef]

149. Gupta, T.; Rajaraman, G. How strongly are the magnetic anisotropy and coordination numbers correlated in lanthanide based molecular magnets? J. Chem. Sci. 2014, 126, 1569-1579. [CrossRef]

150. Dey, S.; Rajaraman, G. In silico design of pseudo $\mathrm{D}_{5 \mathrm{~h}}$ actinide based molecular magnets: Role of covalency in magnetic anisotropy. J. Chem. Sci. 2019, 131, 124. [CrossRef]

151. Vonci, M.; Giansiracusa, M.J.; Gable, R.W.; van den Heuvel, W.; Latham, K.; Moubaraki, B.; Murray, K.S.; Yu, D.H.; Mole, R.A.; Soncini, A.; et al. Ab initio calculations as a quantitative tool in the inelastic neutron scattering study of a single-molecule magnet analogue. Chem. Commun. 2016, 52, 2091-2094. [CrossRef]

152. Pineda, E.M.; Chilton, N.F.; Tuna, F.; Winpenny, R.E.P.; McInnes, E.J.L. Systematic Study of a Family of Butterfly-Like $\left\{\mathrm{M}_{2} \mathrm{Ln}_{2}\right\}$ Molecular Magnets $\left(\mathrm{M}=\mathrm{Mg}^{\mathrm{II}}, \mathrm{Mn}^{\mathrm{III}}, \mathrm{Co}^{\mathrm{II}}, \mathrm{Ni}^{\mathrm{II}}\right.$, and $\mathrm{Cu}^{\mathrm{II}}$; $\mathrm{Ln}=\mathrm{Y}^{\mathrm{III}}, \mathrm{Gd}^{\mathrm{III}}, \mathrm{Tb}^{\mathrm{III}}, \mathrm{Dy}{ }^{\mathrm{III}}, \mathrm{Ho}^{\mathrm{III}}$, and Er $\left.{ }^{\mathrm{III}}\right)$. Inorg. Chem. 2015, 54, 5930-5941. [CrossRef]

153. Mannini, M.; Bertani, F.; Tudisco, C.; Malavolti, L.; Poggini, L.; Misztal, K.; Menozzi, D.; Motta, A.; Otero, E.; Ohresser, P.; et al. Magnetic behavior of $\mathrm{TbPc}_{2}$ single-molecule magnets chemically grafted on silicon surface. Nat. Commun. 2014, 5, 4582. [CrossRef]

154. Valiev, M.; Bylaska, E.J.; Govind, N.; Kowalski, K.; Straatsma, T.P.; van Dam, H.J.J.; Wang, D.; Nieplocha, J.; Apra, E.; Windus, T.L.; et al. NWChem: A comprehensive and scalable open-source solution for large scale molecular simulations. Comput. Phys. Commun. 2010, 181, 1477-1489. [CrossRef] 
155. Prsa, K.; Nehrkorn, J.; Corbey, J.F.; Evans, W.J.; Demir, S.; Long, J.R.; Guidi, T.; Waldmann, O. Perspectives on neutron scattering in lanthanide-based single-molecule magnets and a case study of the $\mathrm{Tb}_{2}\left(\mu-\mathrm{N}_{2}\right)$ system. Magnetochemistry 2016, 2, 45. [CrossRef]

156. Albuquerque, A.F.; Alet, F.; Corboz, P.; Dayal, P.; Feiguin, A.; Fuchs, S.; Gamper, L.; Gull, E.; Gürtler, S.; Honecker, A.; et al. The ALPS project release 1.3: Open-source software for strongly correlated systems. J. Magn. Magn. Mater. 2007, 310, 1187-1193. [CrossRef]

157. Baniodeh, A.; Magnani, N.; Lan, Y.H.; Buth, G.; Anson, C.E.; Richter, J.; Affronte, M.; Schnack, J.; Powell, A.K. High spin cycles: Topping the spin recored for a single molecule verging on quantum criticality. Npj Quantum Mater. 2018, 3, 10. [CrossRef]

158. CP2K Developers Group. CP2K Open Source Molecular Dynamics. Available online: http://www.cp2k.org/ (accessed on 3 July 2021).

159. Burgess, J.A.J.; Malavolti, L.; Lanzilotto, V.; Mannini, M.; Yan, S.C.; Ninova, S.; Totti, F.; Rolf-Pissarczyk, S.; Cornia, A.; Sessoli, R.; et al. Magnetic fingerprint of individual $\mathrm{Fe}_{4}$ molecular magnets under compression by a scanning tunneling microscope. Nat. Commun. 2015, 6, 8216. [CrossRef]

160. Tandon, S.; Schmitt, W.; Watson, G.W. J2suscep: Calculation of magnetic exchange coupling and temperature dependence of magnetic susceptibility. J. Open Source Softw. 2021, 6, 2838. [CrossRef]

161. Smith, D.G.A.; Burns, L.A.; Simmonett, A.C.; Parrish, R.M.; Schieber, M.C.; Galvelis, R.; Kraus, P.; Kruse, H.; di Remigio, R.; Alenaizan, A.; et al. PSI4 1.4: Open-source software for high-throughput quantum chemistry. J. Chem. Phys. 2020, $152,184108$. [CrossRef] [PubMed]

162. Pronk, S.; Páll, S.; Schulz, R.; Larsson, P.; Bjeklmar, P.; Apostolov, R.; Shirts, M.R.; Smith, J.C.; Kasson, P.M.; van der Spoel, D.; et al. GROMACS 4.5: A high-throughput and highly parallel opuen source molecular simulation toolkit. Bioinformatics 2013, $29,845$. [CrossRef] [PubMed]

163. Veloso, S.R.S.; Andrade, R.G.D.; Castanheira, E.M.S. Review on the advancements of magnetic gels: Towards multifunctional magnetic liposome-hydrogel composites for biomedical applications. Adv. Colloid Interface Sci. 2021, 288, 102351. [CrossRef]

164. Rusakov, V.; Raikher, Y. Magnetorelaxometry in the presence of a DC bias field of ferromagnetic nanoparticles bearing a viscoelastic corona. Sensors 2018, 18, 1661. [CrossRef]

165. Kurlyandskaya, G.V.; Litvinova, L.S.; Safronov, A.P.; Schupletsova, V.V.; Tyukova, I.S.; Khaziakhmatova, O.G.; Slepchenko, G.B.; Yurova, K.A.; Cherempey, E.G.; Kulesh, N.A.; et al. Water-based suspensions of iron oxide nanoparticles with electrostatic or steric stabilization by chitosan: Fabrication, characterization and biocompatibility. Sensors 2017, 17, 2605. [CrossRef]

166. Domingo, N.; Bellido, E.; Ruiz-Molina, D. Advances on structuring, integration and magnetic characterization of molecular nanomagnets on surfaces and devices. Chem. Soc. Rev. 2012, 41, 258-302. [CrossRef] [PubMed]

167. Vaheb, Y.; Calvet, L.E.; Dia, N.; Mallah, T.; Catala, L. Assembly of molecular nanomagnets into nanogap electrodes by dielectrophoresis. J. Nanosci. Nanotechnol. 2012, 12, 8710-8714. [CrossRef] [PubMed]

168. Messina, P.; Mannini, M.; Caneschi, A.; Gatteschi, D.; Sorace, L. Spin noise fluctuations from paramagnetic molecular adsorbates on surfaces. J. Appl. Phys. 2007, 101, 053916. [CrossRef]

169. Fonin, M.; Voss, S.; Herr, S.; de Loubens, G.; Kent, A.D.; Burgert, M.; Groth, U.; Rüdiger, U. Influence of the ligand shell on the surface orientation of $\mathrm{Mn}_{12}$ single molecule magnets. Polyhedron 2009, 28, 1977-1981. [CrossRef]

170. Jia, J.-H.; Li, Q.-W.; Chen, Y.-C.; Liu, J.-L.; Tong, M.-L. Luminescent single-molecule magnets based on lanthanides: Design strategies, recent advances and magneto-luminescent studies. Coord. Chem. Rev. 2019, 378, 365-381. [CrossRef]

171. Yi, X.H.; Bernot, K.; Pointillart, F.; Poneti, G.; Calvez, G.; Daiguebonne, C.; Guillou, O.; Sessoli, R. A luminescent and sublimable Dy III-based single-molecule magnet. Chem. A Eur. J. 2012, 18, 11379-11387. [CrossRef]

172. Jiménez, J.-R.; Díaz-Ortega, I.F.; Ruiz, E.; Aravena, D.; Pope, S.J.A.; Colacio, E.; Herrera, J.M. Lanthanide tetrazolate complexes combining single-molecule magnet and luminescence properties: The effect of the replacement of tetrazolate $\mathrm{N}_{3}$ by $\beta$-diketonate ligands on the anisotropy energy barrier. Chem. A Eur. J. 2016, 22, 14548-14559. [CrossRef]

173. Wang, J.H.; Zakrzewski, J.J.; Heczko, M.; Zychowsicz, M.; Nakagawa, K.; Nakabayashi, K.; Sieklucka, B.; Chorazy, S.; Ohkoshi, S.-I. Proton conductive luminescent thermometer based on near-infrared emissive $\left\{\mathrm{YbCo}_{2}\right\}$ molecular nanomagnets. J. Am. Chem. Soc. 2020, 142, 3970-3979. [CrossRef]

174. Long, J. Luminescent Schiff-base lanthanide single-molecule magnets: The association between optical and magnetic properties. Front. Chem. 2019, 7, 63. [CrossRef]

175. Long, J.; Ivanov, M.S.; Khomchenko, V.A.; Mamontova, E.; Thibaud, J.-M.; Rouquette, J.; Beaudhuin, M.; Granier, D.; Ferreira, R.A.; Carlos, L.D.; et al. Room temperature magnetoelectric coupling in a molecular ferroelectric ytterbium(III) complex. Science 2020, 367, 671-676. [CrossRef] [PubMed]

176. Sato, T.; Katoh, K.; Breedlove, B.K.; Yamashita, M. Electro-conductive single-molecule magnet composed of a dysprosium(III)phthalocyaninato double-decker complex with magnetoresistance. Angew. Chem. Int. Ed. 2021. early view. [CrossRef] [PubMed]

177. Guo, P.-H.; Meng, Y.; Chen, Y.-C.; Li, Q.-W.; Wang, B.-Y.; Leng, J.-D.; Bao, D.-H.; Jia, J.-H.; Tong, M.-L. A zigzag Dy ${ }_{4}{ }_{4}$ cluster exhibiting single-molecule magnet, ferroelectric and white-light emitting properties. J. Mater. Chem. C 2014, 2, 8858-8864. [CrossRef]

178. Li, X.-L.; Chen, C.-L.; Gao, Y.-L.; Liu, C.-M.; Feng, X.-L.; Gui, Y.-H.; Fang, S.-M. Modulation of homochiral Dy ${ }^{\mathrm{III}}$ complexes: Single-molecule magnets with ferroelectric properties. Chem. Eur. J. 2012, 18, 14632-14637. [CrossRef] [PubMed] 
179. Bhatt, P.; Mukadam, M.D.; Meena, S.S.; Mishra, S.K.; Mittal, R.; Sastry, P.U.; Mandal, B.P.; Yusuf, S.M. Room temperature ferroelectricity in one-dimensional single chain molecular magnets $\left.\left[\{M(\Delta) M(\Lambda)\}(\text { ox })_{2} \text { (phen }\right)_{2}\right]_{\mathrm{n}}(M=$ Fe and Mn). Appl. Phys. Lett. 2017, 110, 102901. [CrossRef]

180. Bai, Y.-L.; Tao, J.; Wernsdorfer, W.; Sato, O.; Huang, R.-B.; Zheng, L.-S. Coexistence of magnetization relaxation and dielectric relaxation in a single-chain magnet. J. Am. Chem. Soc. 2006, 128, 16428-16429. [CrossRef]

181. Slota, M.; Bogani, L. Combining molecular spintronics with electron paramagnetic resonance: The path towards single-molecule pulsed spin spectroscopy. Appl. Magn. Reson. 2020, 51, 1357-1409. [CrossRef]

182. Aravena, D.; Ruiz, E. Spin dynamics in single-molecule magnets and molecular qubits. Dalton Trans. 2020, 49, 9916-9928. [CrossRef]

183. Zhu, Z.H.; Li, X.-L.; Liu, S.T.; Tang, J.K. External stimuli modulate the magnetic relaxation of lanthanide single-molecule magnets. Inorg. Chem. Front. 2020, 7, 3315-3326. [CrossRef]

184. Kalita, P.; Acharya, J.; Chandrasekhar, V. Mononuclear pentagonal bipyramidal Ln(III) complexes: Syntheses and magnetic properties. J. Magn. Magn. Mater. 2020, 498, 166098. [CrossRef]

185. Tian, H.; Zheng, L.M. Cyclic lanthanide-based molecular clusters: Assembly and single molecule magnet behavior. Acta Chim. Sin. 2020, 78, 34-55. [CrossRef]

186. Chorazy, S.; Zakrzewski, J.J.; Magott, M.; Korzeniak, T.; Nowicka, B.; Pinkowicz, D.; Podgajny, R.; Sieklucka, B. Octacyanidometallates for multifunctional molecule-based materials. Chem. Soc. Rev. 2020, 49, 5945-6001. [CrossRef]

187. Guan, R.N.; Chen, M.Q.; Yang, S.F. Metal fullerene monomolecular magnet. Chin. Sci. Bull. 2020, 65, 2209-2224. [CrossRef]

188. Reczynski, M.; Nakabayashi, K.; Ohkoshi, S.-I. Tuning the optical properties of magnetic materials. Eur. J. Inorg. Chem. 2020, 2020, 2669-2678. [CrossRef]

189. Coronado, E. Molecular magnetism: From chemical design to spin control in molecules, materials and devices. Nat. Rev. Mater. 2020, 5, 87-104. [CrossRef]

190. Hao, G.H.; Cheng, R.H.; Dowben, P.A. The emergence of the local moment molecular spin transistor. J. Phys. Condens. Matter 2020, 32, 234002. [CrossRef]

191. Perlepe, P.S.; Maniaki, D.; Pilichos, E.; Katsoulakou, E.; Perlepes, S.P. Smart ligands for efficient 3d-, 3d- and 5d-metal singlemolecule magnets and single-ion magnets. Inorganics 2020, 8, 39. [CrossRef] 